Anuario da Facultade de Dereito da Universidade da Coruña

Vol. 20 (2016), pp. 29-71

ISSNe: 2530-6324 || ISSN: 1138-039X

DOI: https://doi.org/10.17979/afdudc.2016.20.0.1912

\title{
ANÁLISIS DE LA LEGISLACIÓN ESTATAL Y AUTONÓMICA EN MATERIA DE INSTRUCCIONES PREVIAS O VOLUNTADES ANTICIPADAS
}

\author{
LYDIA NORIEGA RODRÍGUEZ \\ Profesora Ayudante Doctora de Derecho Civil \\ Universidade de Vigo
}

Fecha de recepción: 27.10.2016

Fecha de aceptación: 10.11.2016

\begin{abstract}
Resumen: Las instrucciones previas o voluntades anticipadas han sido objeto de un amplio desarrollo legislativo en nuestro ordenamiento jurídico en los últimos años. Dado que el art. 148.1.21 de la Constitución Española determina que las Comunidades Autónomas podrán asumir la competencia en sanidad e higiene, actualmente existe una extensa legislación estatal y autonómica sobre esta materia. En el presente trabajo, se aproxima una breve exposición de la normativa en vigor; se debe señalar que las diferencias en la regulación de los distintos aspectos de esta institución son notables, lo que provoca que actualmente exista una heterogeneidad legislativa en relación a esta figura jurídica.
\end{abstract}

Palabras clave: Voluntades anticipadas, instrucciones previas, otorgante, consentimiento, autonomía privada

Abstract: The previous instructions or early wills have been an object of a wide legislative development in our juridical classification in the last years. Provided that the art. 148.1.21 of the Spanish Constitution determines that the Autonomous Communities will be able to assume the competition in health and hygiene; nowadays there exists an extensive state and autonomous legislation on this matter. In the present work, a brief exhibition of the regulation comes closer in effect; it is necessary indicate that the differences in the regulation of the different aspects of this institution are notable, which provokes that nowadays a legislative heterogeneity exists in relation to this juridical figure.

Key words: Arly wills, previous instructions, grantor, assent, private autonomy 
SUMARIO: I. INTRODUCCIÓN. II. REFERENCIA A LA REGULACIÓN EN EL ÁMBITO TERRITORIAL ESPAÑOL. 1. Legislación estatal. 1.1. Ley 41/2002, de 14 de noviembre, Básica reguladora de la autonomía del paciente y de derechos y obligaciones en materia de información y documentación clínica. 1.2. Real Decreto 124/2007, de 2 de febrero, que regula el Registro nacional de Instrucciones Previas y el correspondiente Fichero Automatizado de datos de carácter personal. 2. Legislación de las Comunidades Autónomas. 2.1. Comunidad Autónoma de Andalucía. 2.1.1. Ley 5/2003, de 9 de octubre, de declaración de Voluntad Vital Anticipada, de la Comunidad de Andalucía. 2.1.2. Decreto 59/2012, de 13 de marzo, que regula la organización y funcionamiento del Registro de Voluntades Vitales Anticipadas de Andalucía. 2.2. Comunidad Autónoma de Aragón. 2.2.1. Ley 6/2002, de 15 de abril, de Salud de Aragón. 2.2.2. Decreto 100/2003, de 6 de mayo, del Gobierno de Aragón, que aprueba el Reglamento de Organización y del Registro de Voluntades Anticipadas. 2.3. Comunidad Autónoma del Principado de Asturias. 2.3.1. Decreto 4/2008, de 23 de enero, de Organización y Funcionamiento del Registro del Principado de Asturias de Instrucciones Previas en el ámbito sanitario. 2.3.2. Resolución de 29 de abril de 2008, de la Consejería de Salud y Servicios Sanitarios, de Organización y Funcionamiento del Registro del Principado de Asturias de Instrucciones Previas en el ámbito sanitario. 2.4. Comunidad Autónoma de Islas Baleares. 2.4.1. Ley 1/2006, de 3 de marzo, de Voluntades Anticipadas de la Comunidad Autónoma de Islas Baleares. 2.4.2. Decreto 58/2007, de 27 de abril, de ampliación de la Ley de Voluntades Anticipadas y del Registro de Voluntades Anticipadas de las Islas Baleares. 2.5. Comunidad Autónoma de Canarias. 2.5.1. Decreto 13/2006, de 8 de febrero, por el que se regulan las Manifestaciones Anticipadas de Voluntades en el ámbito sanitario y la creación de su correspondiente registro de la Comunidad Autónoma de Canarias y que desarrolla, en esta materia, la Ley 11/1994, de 26 de julio, de Ordenación Sanitaria de Canarias. 2.6. Comunidad Autónoma de Cantabria. 2.6.1 La Ley 7/2002, de 10 de diciembre, de Ordenación Sanitaria de Cantabria. 2.6.2. Decreto 139/2004, de 5 de diciembre, por el que se crea y regula el Registro de Voluntades Previas de Cantabria. 2.7. Comunidad Autónoma de Castilla La Mancha. 2.7.1. Ley 6/2005, de 7 de julio, sobre la Declaración de Voluntades Anticipadas en materia de la propia salud de la Comunidad Autónoma de Castilla La Mancha. 2.7.2. Decreto 15/2006, de 21 de febrero, del Registro de Voluntades Anticipadas de Castilla La Mancha. 2.8. Comunidad Autónoma de Castilla y León. 2.8.1. Ley $8 / 2003$, de 8 de abril, sobre derechos y deberes de las personas en relación con la salud de la Comunidad Autónoma de Castilla y León. 2.8.2. Decreto 30/2007, de 22 de marzo, que regula el Documento de Instrucciones Previas en el ámbito sanitario de Castilla y León. 2.9. Comunidad Autónoma de Cataluña. 2.9.1. Ley 21/2000, de 29 de diciembre, sobre los derechos de información relativos a la salud, la autonomía del paciente y la documentación clínica de la Comunidad Autónoma de Cataluña. 2.9.2. Decreto 175/2002, de 25 de junio, sobre el Registro de Voluntades Anticipadas en Cataluña. 2.10. Ciudades Autónomas de Ceuta y Melilla. 2.11. Comunidad Autónoma de Extremadura. 2.11.1. Ley 3/2005, de 8 de julio, de información sanitaria y autonomía del paciente de la Comunidad Autónoma de Extremadura.2.11.2. Decreto 311/2007, de 15 de octubre, por el que se regula el contenido, la organización y el funcionamiento del Registro de Expresión Anticipada de Voluntades de la Comunidad Autónoma de Extremadura y se crea el Fichero Automatizado de datos de carácter personal del citado Registro. 2.12. Comunidad Autónoma de Galicia. 2.12.1. Ley 3/2001, de 28 de mayo, reguladora del consentimiento informado y de la historia clínica de los pacientes, modificada por la Ley 3/2005, de 7 de marzo de Galicia. 2.12.2. Decreto 159/2014, de 11 de diciembre, 
que establece la organización y funcionamiento del Registro Gallego de Instrucciones Previas sobre cuidados y tratamiento de la salud. 2.13. Comunidad Autónoma de La Rioja. 2.13.1. Ley 9/2005, de 30 de septiembre, reguladora del Documento de Instrucciones Previas en el ámbito de la sanidad de la Comunidad Autónoma de La Rioja. 2.13.2. Decreto 30/2006, de 19 de mayo, por el que se regula el Registro de Instrucciones Previas de La Rioja. 2.13.3. Orden 8/2006, de 26 de julio, de la Consejería de Salud, sobre la forma de otorgar documento de Instrucciones Previas ante personal de la Administración. 2.14. Comunidad Autónoma de Madrid. 2.14.1. Ley 3/2005, de 23 de mayo, por la que se regula el ejercicio del derecho a formular Instrucciones Previas en el ámbito sanitario y se crea el Registro correspondiente de la Comunidad Autónoma de Madrid. 2.14.2. Decreto 101/2006, de 16 de noviembre, del Consejo de Gobierno, por el que se regula el Registro de Instrucciones Previas de la Comunidad de Madrid. 2.14.3. Orden 2191/2006, de 18 de diciembre, por el que regula el Registro de Instrucciones Previas de la Comunidad de Madrid y establece los modelos oficiales de los documentos de solicitud de inscripción de las Instrucciones Previas y de su revocación, modificación o sustitución. 2.15. Comunidad Autónoma de Murcia. 2.15.1. Decreto 80/2005, 19 de julio, que aprueba el Reglamento de Instrucciones Previas y su Registro de la Comunidad Autónoma de Murcia. 2.16. Comunidad Autónoma de Navarra. 2.16.1. Ley Foral 17/2010, 8 de noviembre, Derechos y deberes de las personas en materia de salud en la Comunidad Foral de Navarra. 2.16.2. Decreto Foral 140/2003, de 16 de junio, por el que se regula el Registro de Voluntades Anticipadas de la Comunidad Autónoma de Navarra. 2.17. Comunidad Autónoma del País Vasco. 2.17.1. Ley 7/2002, de 12 de diciembre, de las voluntades anticipadas en el ámbito de la sanidad de la Comunidad Autónoma del País Vasco. 2.17.2. Decreto 270/2003, de 4 de noviembre, del Gobierno Vasco, por el que se crea el Registro de Voluntades Anticipadas. 2.18. Comunidad Autónoma de Valencia. 2.10.1. Ley 10/2014, de 29 de diciembre, de Salud de Valencia. 2.10.2. Decreto 168/2004, de 10 de septiembre, del Consejo de la Generalitat, que regula el Documento de Voluntades Anticipadas y crea el Registro Centralizado de Voluntades Anticipadas de la Comunidad Valenciana. III. CONSIDERACIONES FINALES

\section{INTRODUCCIÓN}

Los extraordinarios avances médicos y científicos producidos en las últimas décadas han propiciado el desarrollo de técnicas cada vez más sofisticadas que permiten la superación de un mayor número $\mathrm{y}$, hasta hace poco, procesos incurables. No obstante, también han dado lugar a situaciones en las que personas en estado terminal o en coma son mantenidas artificialmente con vida de forma indefinida, generándose un debate ético-jurídico sobre quién puede decidir sobre su continuación o desconexión cuando el paciente no puede expresar por sí mismo su opinión. Es este contexto dónde surgen los documentos de instrucciones previas, configurados fundamentalmente como un medio para que el otorgante pueda manifestar su voluntad sobre las técnicas y cuidados que deben serle prestados así como aquellos que no desea le sean aplicados para los supuestos en que se encuentre incapacitado para emitir tal declaración.

La regulación de esta institución nace en EEUU por dos casos de triste celebridad, los conocidos como caso Quinlan y Cruzman. En el primero de ellos, una joven, Karen Ann Quinlan, debido al consumo de alcohol y barbitúricos durante una fiesta quedó en situación de coma irreversible. Trasladada a la Unidad de Cuidados Intensivos, se le 
conectó a un respirador volumétrico y era alimentada mediante sonda nasogástrica. Ante la irreversibilidad del coma, los padres se plantearon la retirada del respirador artificial para no seguir manteniendo su vida. Por su parte, el equipo jurídico del hospital consideró que este comportamiento podría ser contraria a la ética y además constitutiva de un delito, dado que Karen era mayor de edad y sus progenitores ya no ostentaban su representación, por lo que no podían decidir por ella. Los progenitores decidieron presentar una demanda judicial solicitando su representación legal. Tras su concesión, solicitaron judicialmente la desconexión de su hija del respirador artificial. Durante el juicio, declararon que su hija había afirmado en diversas ocasiones que no deseaba ser mantenida con vida de forma artificial. Tras ser rechazada en Primera Instancia las pretensiones de los padres, se recurrió ante la Corte Suprema del Estado de Nueva Jersey. El 31 de marzo de 1976, daba la razón a los padres de Karen, alegando que si no había posibilidades razonables de curación, los medios de soporte vital deberían ser retirados, sin que dicha actuación supusiese culpabilidad civil o penal para el tutor, el equipo médico o el hospital. No obstante, tras la desconexión del respirador siguió respirando por sus propios medios y sus padres decidieron no retirarle la sonda gástrica, pese a la autorización de la Corte Suprema. Murió en 1985, tras 10 años de vida exclusivamente vegetativa.

En el segundo, Nancy Beth Cruzman, tras sufrir un accidente de tráfico quedó en estado vegetativo persistente. Sus padres y representantes legales solicitaron judicialmente la retirada de la sonda gástrica a través de la que se alimentaba, alegando la irreversibilidad de su situación y que ella había manifestado ante testigos su deseo de no seguir viviendo si algún día se encontraba en un estado de coma. El Juez de Primera Instancia falló a su favor, pero la sentencia fue recurrida por el Fiscal General del Estado ante la Corte Suprema de Missouri, revocando la resolución de Primera Instancia, arguyendo que las pruebas testificales sobre las declaraciones emitidas por la paciente no eran claras ni convincentes. Los padres apelaron al Tribunal Supremo resolvió que respecto a los pacientes incapaces si no existían testamentos vitales, las decisiones sobre los tratamientos médicos a aplicar debían someterse a los requisitos de control establecidos legalmente en cada Estado.

A raíz de estas decisiones judiciales, se generalizó el otorgamiento de los testamentos vitales, denominados "Advance Directive". La expresión escrita del citado documento en el que el declarante expresa de forma consciente y concreta sus deseos para ser aplicado en los supuestos en que no pueda decidir, supone una prueba de inestimable valor para determinar la actuación de los facultativos, y en su caso, de los propios jueces en estos casos concretos.

\section{REFERENCIA A LA REGULACIÓN EN EL TERRITORIAL ESPAÑOL}

En nuestro país, como en el resto del Derecho comparado y basado fundamentalmente en el desarrollo legislativo que, como se dijo, se produjo en EEUU, de forma paulatina se fueron aprobando normas para regular esta situación, dando lugar a una normativa heterogénea sobre esta temática.

En el ámbito estatal, puede considerarse como principio angular de esta regulación, el reconocimiento del derecho a la protección de la salud para todos los 
ciudadanos, recogidos en los arts. 41 y 43 de la Constitución Española de 1978 (en adelante C.E.).

Por otro lado, como es sabido el art. 137 C.E. dispone la división territorial del Estado en municipios, en provincias y en Comunidades Autónomas. Asimismo, en los arts. 148 y 149 del citado texto legal se establecen las competencias que pueden asumir las CCAA y las que son exclusivas del Estado, respectivamente. En relación a los servicios sanitarios, en el art. 149.1.16 C.E. se establece que el Estado regulará la Sanidad exterior así como las bases y coordinación general de la sanidad. El art. 148.1.21 de la norma suprema determina que las CCAA podrán asumir la competencia en sanidad e higiene.

En base a este reparto competencial, el Estado aprobó la Ley 14/1986, de 25 de abril, General de Sanidad ${ }^{1}$ norma básica en la que se disponen las bases para la creación del Sistema Nacional de Salud, en coordinación con los Servicios de Salud de las CCAA. Los Estatutos de Autonomía de las Comunidades Autónomas han reconocido amplias competencias en materia de Sanidad, fundamentalmente en el desarrollo y gestión de los servicios sanitarios autonómicos.

En relación a la materia que nos ocupa, en el art. 10.9 de la Ley 14/1986, se reconocía el derecho del paciente a rechazar un tratamiento si éste pudiera ocasionarle un trato inhumano o degradante. Con posterioridad, se promulgó la actualmente en vigor Ley 41/2002, de 14 de noviembre, Básica reguladora de la autonomía del paciente y de derechos y obligaciones en materia de información y documentación clínica ${ }^{2}$.

El antecedente legislativo de esta norma es, como se reconoce en su Exposición de Motivos, el conocido como Convenido de Oviedo porque fue en esta ciudad dónde se aprobó por el Comité de Ministros del Consejo de Europa el 4 de abril de 1997 el Convenio sobre Derechos Humanos y Biomedicina. En su art. 9 se dispone que "serán tomados en consideración los deseos expresados anteriormente respecto a una intervención médica por un paciente que, en el momento de la intervención, no se encuentre en situación de expresar su voluntad"3; fue ratificado por España el 23 de julio de 1999 y entró en vigor el 1 de enero de 2000.

Conforme al mandato constitucional, el legislador ha establecido el carácter de Ley Básica de la citada normativa, como se recoge en su D.A. $1^{\mathrm{a}^{4}}$, lo que implica que el Estado establece el marco legal previo y las CCAA el desarrollo normativo ${ }^{5}$. Así se ha cumplido, pues la Ley 41/2002 dedica sólo el art. 11 a las instrucciones previas en el que se estipula el contenido mínimo: voluntad del otorgante respecto a los cuidados y

\footnotetext{
B.O.E. n. 101, 29 de abril de 1986, p. 15207.

2 B.O.E. n. 274, 15 de noviembre de 2002, p. 40126.

3 Vid., BELLVER CAPELLA, V., "Pasos hacia una bioética universal: el Convenio Europeo sobre Derechos Humanos y Biomedicina", coord. ROMEO CASABONA, C.M., El Convenio de Derechos Humanos y Biomedicina. Su entrada en vigor en el ordenamiento jurídico español, Publicaciones de la Cátedra Interuniversitaria, Fundación BBVA, Diputación Foral de Vizcaya, de Derecho y Genoma Humano-Editorial Comares, Bilbao-Granada, 2002, pp. 56-57.

4 “Esta Ley tiene la condición de básica, de conformidad con lo establecido en el artículo $149.1 .1^{a}$ y $16^{a}$ de la Constitución.

El Estado y las Comunidades Autónomas adoptarán, en el ámbito de sus respectivas competencias, las medidas necesarias para la efectividad de esta ley".

${ }^{5}$ REBOLLEDO DELGADO, L., "Derecho Constitución I”, ed. Dykinson, Madrid, 2011, p. 525.
} 
tratamientos que le deben ser aplicados, el destino de su cuerpo u órganos, límites legales de las estipulaciones, la exigencia de forma escrita para su constitución y revocación sin que se estipule la forma de formalización o modificación.

En el apartado 2 de este artículo se dispone que cada servicio de salud desarrollará la legislación sobre las instrucciones previas en su ámbito territorial. De esta forma, las CCAA, en el ejercicio de sus atribuciones, han aprobado su propia normativa, desarrollando aspectos fundamentales de la figura tales como el procedimiento para su otorgamiento, momento temporal en que son eficaces, posibilidad de modificación, sustitución y revocación, limitaciones del contenido del documento...De esta forma, actualmente existe en nuestro país un extenso desarrollo legislativo sobre este derecho fundamental, produciendo un anagrama de difícil conciliación que requiere una cierta uniformidad en su regulación ${ }^{6}$.

En este sentido, se debe señalar que son diversas las expresiones utilizadas para designar el documento al que hacemos referencia. Sin duda, testamento vital es el término más conocido por la ciudadanía aunque curiosamente no se ha consagrado en ningún texto legal del ámbito territorial español. Por el contrario, el vocablo más utilizado por las legislaciones territoriales es el de voluntades anticipadas, aunque en las leyes de las Comunidades de Madrid, de la Rioja y de Murcia se denominan instrucciones previas, al igual que en la norma estatal; declaración de voluntad vital anticipada en la de Andalucía; voluntad previa en la de Cantabria; manifestaciones anticipadas de voluntades en Canarias y expresión anticipada de voluntades en la de Extremadura.

Asimismo, desde otros sectores también han sido denominadas como directrices previas, directrices anticipadas, testamentos de vida o en vida, testamentos biológicos, declaraciones vitales, planificaciones anticipadas de tratamientos, voluntades previas, voluntades vitales anticipadas... Desde el punto de vista jurídico, no parece adecuada esta dispersión lingüística dada la confusión que crea y además su importancia exige una mayor coordinación entre los distintos legisladores ${ }^{7}$. Se ha planteado, asimismo, si esta diferencia es sólo semántica o afecta al propio contenido del documento, considerando la mayoría de la doctrina que es la misma figura ${ }^{8}$.

Respecto al contenido de las normas estatal y autonómicas, y sin perjuicio de su posterior exposición, podemos afirmar que todas ellas permiten al otorgante expresar los criterios que deben guiar la actuación médica, en particular, las relacionadas con las medidas terapéuticas que no desean les sean aplicadas (fundamentalmente, medidas de soporte vital: reanimación cardiopulmonar, diálisis, conexión a un respirador, nutrición e hidratación artificial... $)^{9}$. Por otro lado, la totalidad de las legislaciones contemplan la designación de un representante que actuará conforme a lo establecido en el documento cuando el representado no pueda expresarse o decidir por sí mismo. No obstante, se

\footnotetext{
${ }^{6}$ ALONSO OLEA, M., "El consentimiento informado en medicina y cirugía", R.A.P, n. 155, 2001, p. 25.

${ }^{7}$ Entre otros, LÓPEZ SÁNCHEZ, C., Testamento vital y voluntad del paciente, ob. cit. pp. 93 y ss; RODRÍGUEZ-ARIAS VAIHE, D., Una muerte razonable, ob. cit., p. 37; MONTALVO JAASKELAAINEN, F., Muerte digna y Constitución. Los límites del testamento vital, ed. Publicaciones de la Universidad Pontificia Comillas. Madrid, 2009, p. 49; SIURANA, J.C., Voluntades anticipadas. Una alternativa a la muerte solitaria, ed. Trotta, Madrid, 2005, pp. 36 y 37.

${ }^{8}$ Así lo resalta MONTALVO JAASKELAAINEN, F., Muerte digna y Constitución. Los límites del testamento vital, ob. cit., pp. 50 y ss.

${ }^{9}$ BROGGI M.A., "El documento de voluntades anticipadas". Medicina Clínica, n. 117, 2001, pp. 114-5.
} 
debe señalar que las facultades del representante varían entre las distintas legislaciones, así como los requisitos exigidos para desarrollar esta función. Además, se permite al otorgante plasmar su voluntad sobre la donación de su cuerpo o de sus órganos.

En referencia a los requisitos que debe cumplir el otorgante, las disposiciones normativas del territorio español exigen mayoría de edad, capacidad plena y que se realice de forma libre; se exceptúan, la CCAA de Andalucía que incluye a los menores emancipados y a los incapacitados judiciales en tanto la sentencia de incapacitación no disponga lo contrario; la de Aragón que además de los citados anteriormente, también la extiende a los menores de 14 años con consentimiento de sus representantes legales; la de Valencia que permite su otorgamiento por menores emancipados y la de Navarra que la reconoce a los menores con capacidad suficiente según criterios determinados en la Ley Foral.

En relación al procedimiento de formalización del documento de instrucciones previas, indicar que la norma estatal exige únicamente su forma escrita. En las distintas normativas autonómicas, el proceso estipulado es prácticamente idéntico; se puede realizar ante Notario, dos o tres testigos o funcionario o personal habilitado, con la excepción de las CCAA de Cataluña y Extremadura que no contemplan este último supuesto. Además, la totalidad de las Autonomías recogen la posibilidad de modificación y revocación de los citados documentos.

Por otro lado, de forma unánime, las normativas del territorio español han establecido unos límites legales para la aplicación de los documentos de voluntad anticipada que son a- la voluntad expresada no sea contraria al ordenamiento jurídico vigente, b- no sean contrarias a la buena práctica clínica, la ética profesional o la mejor evidencia científica posible, c- la situación clínica no sea la prevista y no se corresponda con los supuestos previstos al firmar el documento ${ }^{10}$.

Por último, se regula la creación de los Registros para la inscripción de los citados documentos. En el ámbito estatal, se ha aprobado el RD 124/2007, de 2 de febrero, por el que se regula el Registro nacional de instrucciones previas y el correspondiente fichero automatizado de datos de carácter personal ${ }^{11}$, estipulando el procedimiento para que todas las declaraciones de voluntad emitidas sobre esta materia sean registradas en el mismo así como las personas legitimadas para su acceso. En relación a la regulación de los Registros Autonómicos, la totalidad de las CCAA han aprobado sus propios textos normativos sobre esta materia.

En cada norma autonómica se designa a un encargado del Registro, que puede ser un funcionario o personal habilitado, que desempeñará las funciones estipuladas en la normativa vigente; entre otras: incorporación y custodia de los documentos de voluntades anticipadas, información y asesoramiento, acceso y consulta.... Respecto al procedimiento de inscripción, los documentos deben cumplir los requisitos exigidos para el otorgamiento de las instrucciones previas, siendo verificado por el encargado, que los inscribirá si procede o se concederá un plazo para la subsanación de los posibles errores. De forma preceptiva, como se contempla en el RD 124/2007, se debe enviar

\footnotetext{
${ }^{10}$ SOLSONA DURÁN, J.F., "Voluntades anticipadas: una herramienta para anticipar acontecimientos y facilitar la asistencia urgente". Emergencias 2007; n. 19, pp. 239-240.

${ }^{11}$ B.O.E. n. 40,15 de febrero de 2007, p. 6591
} 
telemáticamente la información y la copia del documento de voluntades anticipadas al Registro Nacional. En la totalidad de las legislaciones autonómicas, se permite la modificación y revocación de los citados documentos $\mathrm{y}$, por tanto, su posterior inscripción. Por último, se determinan las personas legitimadas para acceder al contenido del Registro; en líneas generales, otorgante, representante, personal de centros sanitarios, médicos que acrediten que el otorgante no se encuentra en condiciones para decidir por sí mismo....

Respecto a la relación entre el Registro nacional y los autonómicos, la propia normativa estatal es clara al estipular el procedimiento: el encargado del Registro autonómico debe remitir por vía telemática en el plazo de siete días los datos, información mínima así como una copia del documento de instrucciones previas registrado. Se procederá a su inscripción, notificándose en el plazo de siete días y de forma telemática al registro correspondiente. Se pretende de esta forma que todos los documentos de voluntades anticipadas sean inscribibles en el Registro nacional en aras a su conocimiento y eficacia en todo el territorio nacional.

En este punto, realizaremos una breve exposición sobre el contenido de las distintas legislaciones promulgadas en el territorio español.

\section{Legislación estatal}

1.1. Ley 41/2002, de 14 de noviembre, Básica reguladora de la autonomía del paciente y de derechos y obligaciones en materia de información y documentación clínica

Como se expuso, la Ley 41/2002 dedica el art. 11 a la regulación de las instrucciones previas, entendiendo por tales las manifestaciones anticipadas de la voluntad del otorgante que deben ser cumplidas cuando no pueda emitirlas personalmente. Los requisitos exigidos son que el declarante sea mayor de edad, con capacidad plena y que actúe de forma libre. En relación al contenido, se pueden incluir en el documento estipulaciones sobre los cuidados y el tratamiento de su salud o, tras el fallecimiento, determinar el destino de su cuerpo o de sus órganos. Además, permite el nombramiento de un representante que actúe como su interlocutor ante el facultativo o el equipo médico que le atienda, con el propósito de que se cumplan las instrucciones previas.

No establece la norma los procedimientos para su formalización, disponiendo únicamente que debe realizarse por escrito. Estipula que cada servicio sanitario regulará las medidas necesarias para que se garantice el cumplimiento de las instrucciones previas de los pacientes.

En relación a los límites de las voluntades, señala que no se aplicarán aquellas contrarias al ordenamiento jurídico, a la lex artis ni las que no se correspondan con el supuesto de hecho que el interesado haya previsto en el momento de otorgarlas, debiendo quedar constancia razonada de las anotaciones relacionadas con estas previsiones en la historia clínica del paciente. 
Asimismo, se contempla la posibilidad de revocar el documento en cualquier momento, en tanto conste por escrito.

En el último punto, se dispone la creación del Registro nacional de instrucciones previas adscrito al Ministerio de Salud y Consumo, con la finalidad de dotar de eficacia en el territorio español a las instrucciones previas otorgadas por los pacientes conforme a los requisitos establecidos en cada CCAA. Su funcionamiento se regulará reglamentariamente, previo acuerdo del Consejo Interterritorial del Sistema Nacional de Salud. Se ha hecho efectivo mediante el Real Decreto 124/2007, de 2 de febrero, que regula el Registro nacional de instrucciones previas y el correspondiente fichero automatizado de datos de carácter personal ${ }^{12}$.

\subsection{Real Decreto 124/2007, de 2 de febrero, que regula el Registro nacional de instrucciones previas y el correspondiente fichero automatizado de datos de carácter personal}

Consta el texto jurídico de 5 artículos, 2 Disposiciones Adicionales, 1 Disposición Transitoria y 3 Disposiciones Finales. En el propio Preámbulo se determina que su aprobación obedece al mandato establecido por el legislador estatal en el punto 5 del art. 11 de la Ley 41/2002, de 14 de noviembre, Ley básica reguladora de la autonomía del paciente y de derechos y obligaciones en materia de información y documentación clínica. En el art. $1^{\mathrm{o}}$ se dispone su creación y su adscripción al Ministerio de Sanidad y Consumo a través de la Dirección General de Cohesión del Sistema Nacional de Salud y Alta Inspección. En él se recogerán las inscripciones practicadas en los registros autonómicos.

En el art. 2 se determina que la finalidad de la inscripción de las instrucciones previas formalizadas conforme a lo regulado en cada CCAA en el Registro nacional, es posibilitar su conocimiento y eficacia en todo el territorio español. Asimismo, mediante el mismo se pretende la constatación de la existencia de instrucciones previas inscritas en los distintos registros autonómicos, su localización, fecha de inscripción así como la eventual modificación, sustitución y revocación de las mismas y el contenido de los citados documentos.

Se regula en el art. 3 el procedimiento registral y consta de las siguientes fases:

- Cuando se inscriba un documento de voluntades anticipadas o instrucciones previas en un registro autonómico, el encargado de éste debe remitir, vía telemática y en el plazo de siete días tras la inscripción, los datos e información mínima recogida en el Anexo del R.D., así como una copia del documento de instrucciones previas registrado. Tras la recepción de la citada documentación, se procederá a su inscripción así como a la copia de las instrucciones previas en el Registro nacional, notificándose este hecho al Registro autonómico en el término de siete días y de forma telemática. Si existe cualquier tipo de defecto subsanable, se procederá a la inscripción provisional y se requerirá al Registro autonómico para su subsanación en un plazo que no podrá superar los 15 días. En caso de no suplir la omisión o corregir el defecto advertido, se denegará la inscripción sin más trámites, sin perjuicio de su eficacia transitoria y provisional hasta ese momento.

\footnotetext{
${ }^{12}$ B.O.E. n. 40,15 de febrero de 2007 , p. 6591.
} 
En relación a las personas legitimadas para acceder al Registro nacional de instrucciones previas, el art. 4 señala las siguientes: personas otorgantes de instrucciones previas y registradas en él, representantes legales de los declarantes o los que hubiesen sido designados de manera fehaciente por ellos, responsables acreditados de los registros autonómicos, las personas designadas por la autoridad sanitaria de la Comunidad Autónoma correspondiente o por el Ministerio de Sanidad y Consumo.

Para ello deberán presentar la oportuna solicitud escrita al encargado del Registro, quien tras comprobar su identidad, expedirá la oportuna certificación acreditativa.

Por otro lado, establece la norma que los responsables de los Registros autonómicos y las personas designadas por la autoridad sanitaria de la Comunidad Autónoma y por el Ministerio de Sanidad y Consumo podrán acceder al Registro nacional a través de comunicación telemática, previa solicitud del facultativo que estuviese tratando al otorgante, según las condiciones establecidas en el propio texto legal ${ }^{13}$ pudiendo, asimismo, las personas designadas por las autoridades sanitarias de las CCAA acceder al Registro nacional a través de sus propios Registros autonómicos, según lo establecido en cada caso.

Cualquier persona que por razón de su cargo u oficio, tenga acceso a los datos contenidos en el Registro, queda obligada a guardar secreto sobre los mismos.

En el art. 5 se recoge la creación, por parte del Ministerio de Sanidad y Consumo mediante orden ministerial, del fichero automatizado de datos de carácter personal denominado Registro nacional de instrucciones previas, conforme a lo establecido en la Ley Orgánica 15/1999, de 13 de diciembre, de Protección de Datos de Carácter Personal $^{14}$, con el fin de facilitar el conocimiento sobre la existencia y localización de las inscripciones de los documentos de instrucciones previas.

Se adoptarán las medidas necesarias para asegurar la confidencialidad, seguridad e integridad de los datos comprendidas en el Reglamento de Medidas de Seguridad de los Ficheros Automatizados que contengan Datos de Carácter Personal, aprobado por el Real Decreto 994/1999, de 11 de junio, que aprueba el Reglamento de medidas de seguridad de los ficheros automatizados que contengan datos de carácter personal ${ }^{15}$, así como las necesarias para hacer efectivos los derechos de las personas afectadas regulados en la Ley Orgánica 15/1999, de 13 de diciembre, y disposiciones que la desarrollan.

\footnotetext{
13“'A tal efecto, deberán disponer de un certificado de clase 2 CA emitido por la Fábrica Nacional de Moneda y Timbre-Real Casa de la Moneda o de un certificado de firma electrónica reconocida, emitido por un prestador de servicios de certificación homologado, conforme a las prescripciones sectoriales y a la legislación de firma electrónica. A tal fin, se establece un sistema que garantice técnicamente la identificación de la persona destinataria de la información, la integridad de la comunicación, la disponibilidad las 24 horas del día, la conservación de la información comunicada y la confidencialidad de los datos".

${ }^{14}$ B.O.E. n. 298,14 de diciembre de 1999 , p. 43088.

${ }^{15}$ B.O.E. n. 151,25 de junio de 1999, p. 24241.
} 
En las D.A. $1^{\mathrm{a}}$ y $2^{\mathrm{a}}$ se impone la obligación a las CCAA y a las ciudades de Ceuta y Melilla de remitir todas las inscripciones realizadas en los Registros autonómicos y copias de los documentos de instrucciones previas, cumplimentando la información mínima recogida en el Anexo.

En la D.T. se estipula que si en una CCAA no se ha regulado el procedimiento para otorgar el documento de instrucciones previas, el interesado, representante legal o cualquier persona designada a tal efecto, podrá presentarlo ante la autoridad sanitaria de dicha CCAA, quien deberá remitirlo al Registro nacional en el plazo y condiciones fijadas en el art. 3 del RD para su inscripción provisional y que se notificará al órgano autonómico.

En tanto se cree el correspondiente Registro autonómico, estos documentos quedarán en depósito y bajo la custodia del Registro nacional. Una vez creado, el Registro nacional le entregará las instrucciones previas y documentos depositados en él en la forma establecida en el apartado anterior, notificándolo al mismo tiempo a los interesados su entrega.

Realizada la inscripción en el Registro autonómico, será comunicada al Registro nacional en el plazo de siete días, adquiriendo carácter definitivo la inscripción provisional. Para el acceso al Registro de estas instrucciones se estará a lo dispuesto en el art. 4.

\section{Legislación de las Comunidades Autónomas}

\subsection{Comunidad Autónoma de Andalucía}

\subsubsection{Ley 5/2003, de 9 de octubre, de declaración de Voluntad Vital Anticipada, de la Comunidad de Andalucía ${ }^{16}$}

La citada norma consta de 8 artículos, 1 Disposición Adicional y 2 Disposiciones Finales. En el primer artículo se determina el objeto de la citada norma y en el segundo se aproxima su definición ${ }^{17}$.

En relación al contenido de la declaración de voluntad anticipada, determina la ley que su autor podrá manifestar en la misma: las instrucciones previas que deberán ser respetadas por el personal sanitario cuando se encuentre en situación clínica que le impida manifestar su voluntad, la designación de un representante para que le sustituya en el otorgamiento del consentimiento informado en los casos procedentes, su decisión

\footnotetext{
${ }^{16}$ B.O. Junta Andalucía n. 210, 31de octubre de 2003, p. 22728; B.O.E. n. 279, 21 de mayo de 2003, p. 41231.

17 "A los efectos de esta Ley, se entiende por declaración de voluntad vital anticipada la manifestación escrita hecha para ser incorporada al Registro que esta Ley crea, por una persona capaz que, consciente y libremente, expresa las opciones e instrucciones que deben respetarse en la asistencia sanitaria que reciba en el caso de que concurran circunstancias clínicas en las cuales no pueda expresar personalmente su voluntad".
} 
sobre el transplante de órganos o uno de ellos, conforme a lo establecido en la legislación vigente y los valores vitales que sustenten sus preferencias, art. 3.

Esta declaración puede ser emitida por la persona mayor de edad o por el menor emancipado como dispone el art. 4. Asimismo, los incapacitados judicialmente podrán formular su declaración, salvo que disponga lo contrario la sentencia de incapacitación. No obstante, si los facultativos cuestionaran su capacidad para otorgarla pondrán en conocimiento del Ministerio Fiscal esta circunstancia, quien actuará en consecuencia.

Para la validez de la declaración, el art. 5 estipula que además de la capacidad exigida en el artículo anterior, se requieren los siguientes requisitos: debe constar por escrito con la firma del autor, su identificación, lugar y fecha del otorgamiento. En el caso de que el otorgante no supiera o no pudiera firmar, lo hará por él un testigo a su ruego, plenamente identificado, expresándose la razón que impide firmar al autor.

Por otro lado, el art. 6 declara que será un funcionario público habilitado al efecto por la Consejería competente en materia de salud el que constatará la personalidad y capacidad de la persona autora y que la declaración se realiza conforme a los presupuestos formales estipulados en esta norma.

La declaración de voluntad vital anticipada será eficaz, tras su inscripción en el Registro que prevé la propia Ley en su art. 9, cuando sobrevengan las situaciones previstas en ellas y en tanto se mantengan. De forma expresa, dispone la Ley que lo estipulado en la declaración prevalecerá sobre las opiniones de los familiares, personal sanitario y del representante, art. 7.

La norma contempla la posibilidad de revocar o modificar la declaración de voluntad anticipada. En el primer supuesto, tendrá validez la otorgada en último lugar y si se pretende modificar algún extremo del documento deberá hacerse constar expresamente. El representante puede comunicar al Registro que no desea seguir asumiendo tal función, circunstancia que será comunicada al interesado. Por último, se hace referencia al supuesto de que una persona haya emitido una declaración de voluntad anticipada y posteriormente preste un consentimiento informado para un tratamiento determinado que contraríe lo estipulado en aquélla; en estas circunstancias prevalecerá lo manifestado en el mismo, aunque con posterioridad se encuentre en situación en que no pueda expresar su voluntad, según recoge el art. 8.

El último artículo del texto legal, el art. 9, establece la creación del Registro de Voluntades Vitales Anticipadas con vigencia en el ámbito de la Comunidad Autónoma de Andalucía y adscrito a la Consejería de Salud para la conservación, custodia y accesibilidad de las declaraciones. De forma reglamentaria se regulará su funcionamiento y organización; en cualquier caso, conforme a los principios de confidencialidad y respeto a la legislación de protección de datos personales. Cuando una persona se encuentre en situación de no poder tomar decisiones por sí misma, los profesionales sanitarios deberán comprobar en el Registro si ha otorgado declaración de voluntad vital anticipada y, en su caso, actuar conforme a lo establecido en ella, art. 9.2. 


\subsubsection{Decreto $59 / 2012$, de 13 de marzo, que regula la organización y funcionamiento del Registro de Voluntades Vitales Anticipadas de Andalucía ${ }^{18}$}

Su finalidad, como se dispone en el art. 1, es la "custodia, la conservación y la accesibilidad de las declaraciones de voluntad vital anticipada" emitidas en la CCAA de Andalucía. El art. 2 declara que el Registro será único, aunque su gestión será descentralizada mediante sedes habilitadas, contando con una única persona responsable nombrada por el órgano competente. Se establecen las funciones de la persona responsable del Registro así como las responsables de las sedes habilitadas, los requisitos de las sedes habilitadas y los requisitos de las personas responsables del Registro, en los arts. 4, 5, 6 y 7 respectivamente.

En relación a la inscripción, el art. 8 estipula que la declaración debe ser presentada personalmente por el otorgante y en el supuesto que "esté impedido por enfermedad o discapacidad" podrá solicitar al encargado del Registro, tras la acreditación de su incapacidad, que se desplace a su domicilio o centro sanitario dónde esté ingresado para recibir la solicitud de la inscripción de la misma debiendo, en ambos casos, comprobarse la personalidad y capacidad del autor. Para los supuestos de menores emancipados o personas incapacitadas, se exigen además documentos acreditativos de dicha situación. Verificados todos los requisitos, se procederá a su inscripción, art. 9.

Puede ser revocada en cualquier momento de forma personal en el Registro o si no es posible por causa inhabilitante, se permite que se desplace la persona responsable del Registro al domicilio o centro asistencial dónde se encuentre el otorgante, art. 10.

La legitimación para acceder al Registro, se concede al otorgante, representante designado en la declaración así como a su representante legal si existiese. Además, se permite el acceso a los responsables sanitarios por vía telemática o telefónica, realizándose en condiciones que aseguren la correcta identificación del personal y la confidencialidad del documento consultado, como dispone el art. 11.

Además, se debe señalar que en la CCAA de Andalucía se ha promulgado la Ley 2/2010, de 8 de abril, de Derechos y Garantías de la Dignidad de la Persona en el Proceso de la Muerte.

\subsection{Comunidad Autónoma de Aragón}

\subsubsection{Ley 6/2002, de 15 de abril, de Salud de Aragón ${ }^{19}$}

El art. $15^{20}$ de esta norma ha sido modificado mediante la D.F.1 ${ }^{\text {a }}$ de la Ley 10/2011, de 24 de marzo, de derechos y garantías de la dignidad de la persona en el proceso de morir y de la muerte, de la Comunidad Autónoma de Aragón ${ }^{21}$.

\footnotetext{
${ }^{18}$ B. O. Junta de Andalucía n. 59, 26 de marzo de 2012, p. 40; rect. B.O. Junta de Andalucía n. 107, 1 de junio de 2012, p. 8

${ }^{19}$ B.O. Aragón n. 46, 19 de abril 2002, p. 3741; B.O.E. n. 121, 21 de mayo de 2002, p.18061.

20 "Se entiende por voluntades anticipadas el documento en el que una persona con capacidad legal suficiente, mayor de edad, menor emancipado o menor aragonés mayor de catorce años, en su caso con
} 
En el apartado 5 del art. 15 se exige su constancia por escrito, con identificación del declarante, firma y fecha y lugar del otorgamiento. Se recomienda inscribir el documento en el Registro de voluntades anticipadas y su incorporación a la historia clínica del paciente. El representante debe ser mayor de edad y tener plena capacidad. Debe ser identificado y haber presentado su aceptación para tal función.

Son tres los procedimientos regulados para su formalización: a) ante notario, b) ante dos testigos mayores de edad y con plena capacidad de obrar, de los cuales al menos uno no puede tener relación de parentesco hasta segundo grado ni estar vinculado por relación patrimonial con el otorgante, c) ante el personal habilitado al efecto por el departamento competente en materia de salud.

Los menores emancipados y los menores mayores de catorce años podrán emitir la declaración de voluntades anticipadas según lo establecido en el punto anterior, así como los incapacitados judicialmente, salvo que en la resolución de incapacitación se disponga lo contrario. No obstante, si el personal facultativo considera que no se encuentra en condiciones para otorgarla, lo deberán poner en conocimiento del Ministerio Fiscal quien instará, si procede, ante la autoridad judicial un nuevo proceso de modificación de la resolución anterior.

Cuando se preste asistencia sanitaria a una persona que se encuentre en una situación que le impida tomar decisiones por sí misma, el equipo sanitario consultará la historia clínica del paciente, a sus familiares, allegados o representante o directamente al Registro de Voluntades Anticipadas para comprobar si el sujeto ha otorgado el documento de voluntades anticipadas.

Tras su inscripción en el Registro, deberá constar en la historia clínica del paciente su existencia. Si en la declaración se nombra a un representante, éste deberá actuar buscando el mayor beneficio y el respeto a la dignidad personal y a los valores vitales de su representado, velando en todo caso para que en las actuaciones facultativas se cumplan las instrucciones dadas por el interesado.

En aquellas situaciones clínicas no contempladas explícitamente en la declaración, el representante tendrá en cuenta las opciones u opiniones vitales recogidos en la citada declaración. Asimismo, el autor podrá determinar en su declaración las funciones de su representante y las personas que pueden tener acceso a la misma, así como sus restricciones, como se recoge en el art. 9 de la Ley 10/2011.

la asistencia prevista en el artículo 21 de la Ley 13/2006, de 27 de diciembre, de Derecho de la Persona, libremente puede manifestar:

a) Las opciones e instrucciones, expresas y previas, que, ante circunstancias clínicas que le impidan manifestar su voluntad, deberá respetar el personal sanitario responsable de su asistencia sanitaria.

b) La designación de un representante, plenamente identificado, que será quien le sustituya en el otorgamiento del consentimiento informado, en los casos en que este proceda.

c) Su decisión respecto de la donación de sus órganos o de alguno de ellos en concreto, en el supuesto que se produzca el fallecimiento, de acuerdo con lo establecido en la legislación general en la materia.

d) Los valores vitales que sustenten sus decisiones y preferencias”.

${ }^{21}$ B.O. Aragón n. 70, 7 de abril 2011, p. 7669; B.O.E. n. 115, 14 de mayo de 2011, p. 49076. 


\subsubsection{Decreto 100/2003, de 6 de mayo, del Gobierno de Aragón, se aprueba el Reglamento de Organización y del Registro de Voluntades Anticipadas ${ }^{22}$.}

En el art. 8 se recogen las funciones del Registro: inscripción documentos, facilitar acceso personas legitimadas, coordinación con el Registro Nacional de Instrucciones Previas.

En el art. 9 se regula el procedimiento para su inscripción, estableciendo que puede ser presentado por el autor, sus familiares o allegados y su representante legal. Si la declaración de voluntad se ha formalizado ante testigos, será precisa el documento original que la contenga, fotocopia del documento nacional de identidad o pasaporte del otorgante y de los testigos, debidamente compulsados y su declaración que no se encuentran inhabilitados para tal función. En el supuesto de haberse realizado ante Notario, será suficiente la presentación por cualquier persona de una copia autorizada del mismo.

Por último, las personas legitimadas para el acceso al Registro son el otorgante y su representante legal. Asimismo, en los supuestos en los que el paciente no pueda expresarse por sí mismo, el médico responsable deberá solicitar información al Registro sobre si existe declaración de voluntad emitida por el paciente y, en su caso, conocer su contenido, con independencia que en la historia clínica del paciente conste una copia o no del mismo. Este acceso se realizará por medios telemáticos para garantizar la confidencialidad de los datos e información suministrada y de la identificación de la persona que los solicita.

\subsection{Comunidad Autónoma del Principado de Asturias}

2.3.1. Decreto 4/2008, de 23 de enero, de Organización y Funcionamiento del Registro del Principado de Asturias de Instrucciones Previas en el ámbito sanitario $^{23}$

Como su título indica, la legislación aprobada en la CCAA de Asturias regula la organización y funcionamiento interno del Registro de Instrucciones Previas, dedicando únicamente el art. 2 del citado Decreto a estipular el contenido mínimo del documento de instrucciones previas. Así, mediante el mismo, una persona mayor de edad, capaz y libre, manifiesta anticipadamente su voluntad, para que sea cumplida cuando se encuentre en situaciones en que no sea capaz de expresarla personalmente, sobre los cuidados y el tratamiento de su salud o, una vez llegado el fallecimiento, sobre el destino de su cuerpo o de sus órganos. Además, se permite la designación de un representante que será el interlocutor del otorgante con el equipo sanitario cuando éste no pueda expresar su voluntad. Se exige que la aceptación por parte del otorgante conste en el propio documento de instrucciones previas o en documento posterior siempre que sea inscrito en el Registro. Por último, se establece la posibilidad de que el citado

\footnotetext{
${ }^{22}$ B.O. Aragón n. 64, 28 de mayo de 2003, p. 6438.

${ }^{23}$ B.O. Principado de Asturias n. 31, 7 de febrero de 2008, p. 2353.
} 
documento sea revocado, modificado o sustituido en cualquier momento por el otorgante.

La solicitud para la inscripción podrá realizarse por el otorgante o el representante, art. 9.

En el art. 15 se determinan las personas que pueden acceder al Registro para la consulta del citado documento:

“a) Los otorgantes de los documentos de instrucciones previas inscritos en él. b) Los representantes legales de los otorgantes o los que a tal efecto hubieran sido designados de manera fehaciente por éstos. c) Los profesionales sanitarios que presten asistencia sanitaria al otorgante”.

2.3.2. Resolución de 29 de abril de 2008, de la Consejería de Salud y Servicios Sanitarios, que desarrolla y ejecuta el citado Decreto $^{24}$.

Establece en su apartado noveno cómo debe ser el acceso al Registro por los profesionales sanitarios ${ }^{25}$

\subsection{Comunidad Autónoma de Islas Baleares}

\subsubsection{Ley 1/2006, de 3 de marzo, de voluntades anticipadas de la Comunidad Autónoma de Islas Baleares ${ }^{26}$}

Consta de 8 artículos, 1 Disposición Derogatoria y 2 Disposiciones Finales.

En el primero de ellos se determina el concepto de la figura ${ }^{27}$. En relación a su contenido, la Ley, en su art. 2, permite incluir los siguientes extremos: la manifestación de sus objetivos vitales y sus valores personales, las indicaciones sobre el cuidado de su salud, determinando los tratamientos que quiera recibir o evitar, incluidos los de carácter experimental. En las situaciones críticas e irreversibles, las instrucciones para

\footnotetext{
${ }^{24}$ B.O. del Principado de Asturias n. 105, 7 de mayo de 2008, p. 10056.

${ }^{25}$ 1. Los profesionales sanitarios responsables de la asistencia sanitaria del otorgante, acreditando dicha circunstancia, podrán acceder al contenido del documento de instrucciones previas, siempre que no conste la oposición del otorgante.

2. Por el titular de la Consejería se podrá autorizar a profesionales responsables de la asistencia sanitaria, en centros sanitarios, para acceder telemáticamente al Registro a través de su identificación como usuario del sistema y el uso de la firma electrónica avanzada o clave de acceso otorgada por la Consejería.

3. El sistema de acceso telemático, garantizará técnicamente la identificación de la persona destinataria de la información, la integridad de la comunicación, la conservación de la información comunicada y la confidencialidad de los datos.

${ }^{26}$ B.O. Islas Baleares n. 36, 11 de marzo de 2006, p. 51; B.O.E. n. 81, 5 de abril de 2006, p. 13198.

27 "A efectos de esta Ley, las voluntades anticipadas consisten en una declaración de voluntad unilateral emitida libremente por una persona mayor de edad y con plena capacidad de obrar, mediante la que se indica el alcance de las actuaciones médicas o de otras que sean procedentes, previstas por esta Ley, solamente en los casos en que concurran circunstancias que no le permitan expresar su voluntad".
} 
evitar el padecimiento con medidas terapéuticas adecuadas, aunque supongan el acortamiento del proceso vital, y el no alargamiento de la vida artificialmente ni el atraso del proceso natural de la muerte mediante tratamientos desproporcionados. Asimismo, su decisión sobre los órganos después del fallecimiento para fines terapéuticos y de investigación y la designación de la persona o personas para su representación en cuestiones médicas. Por último, su voluntad sobre la incineración, inhumación u otro destino del cuerpo después de la defunción.

Los requisitos para emitir la declaración se recogen en el art. 3: deberá formalizarse por escrito, constando el nombre, apellidos y número de D.N.I. o documento equivalente del interesado, firma del declarante y fecha y lugar del otorgamiento. En relación a su formalización, la Ley contempla tres posibilidades: aante notario, b- ante la persona encargada del Registro de voluntades anticipadas, cante tres testigos. En este último supuesto, se exige que los testigos sean mayores de edad con plena capacidad de obrar y que conozcan al otorgante.

Este documento se inscribirá en el Registro de Voluntades Anticipadas y, en su caso, en el Registro de donantes de órganos, bien a solicitud del declarante o de uno de los testigos, con el consentimiento del autor que se presume salvo los supuestos de indicación contraria, o bien por el notario, siempre en la forma, plazos y requisitos establecidos reglamentariamente.

Como se dispone en el art. 4 los destinatarios del documento son "los hospitales, las clínicas, los centros de salud, los dispensarios, los médicos u otras personas u organismos a los que corresponda cumplir la voluntad anticipada que se manifiesta”.

Puede también el autor designar a uno o más representantes, debiendo constar en su caso, el nombre, apellidos, y número de D.N.I. o documento equivalente y la firma de la persona o personas designadas así como su aceptación expresa de serlo, debiendo ser mayores de edad y con plena capacidad de obrar.

La designación de los representantes puede ser simultánea o sucesiva. En el supuesto de que se nombre al cónyuge o a la pareja estable o de hecho, la representación queda sin efecto por la interposición de una demanda de nulidad, de separación matrimonial o divorcio o por el cese de la convivencia, salvo que el otorgante manifieste expresamente que la representación continúa vigente, conforme a lo estipulado en el art. 5.

Para el cumplimento efectivo de las instrucciones dadas por el otorgante, la Consejería de Salud y Consumo regulará reglamentariamente el procedimiento oportuno. En los supuestos de objeción de conciencia de algún facultativo al cumplimiento del contenido del documento, deberá ponerlo en conocimiento del interesado o de su representante y de la Consejería que garantizará los profesionales de la Medicina y los recursos sanitarios para atender la voluntad del autor. No tendrán validez las instrucciones contrarias al ordenamiento jurídico o a la buena práctica clínica ni aquellas que no se correspondan con el supuesto de hecho previsto por la persona en el momento de emitirlas. Los supuestos de incumplimiento de las instrucciones serán motivados y anotados en la historia clínica del paciente, art. 6. 
Conforme a lo establecido en el art. 7, cabe la modificación, sustitución o anulación de las voluntades anticipadas en cualquier momento, siempre que el otorgante conserve la capacidad exigida en el art. 3 de la presente Ley.

Por último, el art. 8 dispone la creación del Registro de Voluntades Anticipadas, dependiente de la Consejería de Salud y Consumo, que funcionará conforme a los principios de confidencialidad y de conexión con el Registro nacional de Instrucciones Previas y con los de donantes de órganos. Pueden los establecimientos sanitarios acceder a este Registro en cualquier momento, debiendo la citada Consejería organizar su funcionamiento conforme a esta exigencia de conexión permanente.

2.4.2. Decreto 58/2007, de 27 de abril, de ampliación de la Ley de voluntades anticipadas y del Registro de Voluntades Anticipadas de las Islas Baleares ${ }^{28}$

En relación al mismo, señalar que desarrolla la Ley 6/2002, como se recoge en su primer artículo. En el primer capítulo que comprende los arts. 1-4, se realiza una ampliación sobre determinados puntos del documento de voluntades anticipadas que sin añadir novedades a lo ya regulado en la citada Ley, hace referencia a las siguientes cuestiones: objeto y ámbito de aplicación, formalización, modificación, sustitución o revocación y objeción de conciencia de los facultativos.

En los arts. 5-11, encuadrados en el segundo capítulo, se contiene la regulación sobre la organización y funcionamiento del Registro de últimas voluntades de Islas Baleares.

En el art. 6 se disponen las funciones del Registro: inscripción, custodia, actualización, garantía de acceso a las personas autorizadas, coordinación con Registro de Voluntades Anticipadas con el Registro Nacional de Instrucciones Previas.

Podrá ser presentada en el Registro para su inscripción, el otorgante, cualquiera de los testigos ante los que se haya emitido la declaración y el notario que lo haya autorizado, art. 7.

Respecto a las personas legitimadas para acceder al Registro, el art. 10.2 del Decreto incluye a la persona otorgante, su/s representante/s así como al personal de los centros sanitarios y a los médicos radicados en la CCAA de Islas Baleares.

\subsection{Comunidad Autónoma de Canarias}

2.5.1. Decreto 13/2006, de 8 de febrero, por el que se regulan las manifestaciones anticipadas de voluntades en el ámbito sanitario y la creación de su correspondiente registro de la Comunidad Autónoma de Canarias ${ }^{29}$ y que desarrolla, en esta materia, la Ley 11/1994, de 26 de julio, de Ordenación Sanitaria de Canarias ${ }^{30}$

\footnotetext{
28 B.O. Islas Baleares. n. 70, 10 de mayo de 2007, p. 710.

${ }^{29}$ B.O. Canarias n. 43, 2 de marzo de 2006, p. 4296.

${ }^{30}$ B.O. Canarias n. 96, 5 de agosto de 1994, p. 5501; B.O.E. n. 204, 26 de agosto de 1994, p. 27167.
} 
Este texto legal consta de dos capítulos, en el primero se desarrollan disposiciones generales sobre las voluntades anticipadas y en el segundo se regula el Registro de Manifestaciones Anticipadas de voluntad en el ámbito sanitario.

El primer capítulo consta de ocho artículos. En el primero de ellos se establece el objeto de la norma jurídica y en el segundo se recoge la definición de la manifestación anticipada de voluntad ${ }^{31}$. Los requisitos formales requeridos se recogen en el art. 3; datos identificativos: nombre, apellidos, sexo, domicilio, teléfono y dirección de correo electrónico si los tuviera, número de documento nacional de identidad, pasaporte o número de identificación de extranjeros o cualquier otro documento válido para acreditar las identidades del otorgante, testigos o en su caso representante; número de tarjeta sanitaria o documento de similar naturaleza; lugar, fecha y firmas de la persona otorgante, de los testigos y, en su caso, del representante.

El contenido del citado documento podrá incluir los siguientes extremos, art. 4: las instrucciones y opciones sobre los cuidados y tratamientos médicos, decisiones sobre el destino de su cuerpo tras su defunción así como la donación de sus órganos o tejidos, -el nombramiento de uno o más representantes que actuarán como interlocutores de las instrucciones o valores del otorgante ante el equipo médico o sanitario, debiendo incorporarse su aceptación en el documento, -se pueden recoger además las indicaciones de naturaleza ética, moral o religiosa que expresen sus objetivos vitales y valores personales como orientación al personal médico en la toma de decisiones clínicas y por el contrario, se tendrán por no puestas las manifestaciones contrarias al ordenamiento jurídico, a la lex artis o aquellas que no se correspondan exactamente con el supuesto de hecho que se hubiera previsto al otorgarlas.

En relación al representante, el art. 5 exige que sea perfectamente identificado, mayor de edad y con plena capacidad de obrar. La renuncia a su condición debe ser realizada por el propio representante ante el Registro quien la comunicará al otorgante, pudiendo nombrar un sustituto si así lo desea.

El Decreto habilita tres procedimientos para la formalización de la manifestación de la voluntad anticipada, que siempre deberá constar por escrito, art. 6: a-ante notario, b- ante funcionario encargado del Registro de manifestaciones, c- ante tres testigos. Deberán ser mayores de edad, con plena capacidad de obrar, no pudiendo ser el cónyuge o persona con la que se mantenga una relación de afectividad análoga a la marital, ni parientes hasta el segundo grado de consanguinidad o afinidad o relación laboral, patrimonial o de servicios.

La manifestación de la voluntad anticipada prevalecerá sobre la opinión de terceras personas, y sólo dejará de tener eficacia si el otorgante emite una posterior declaración de voluntad ante un determinado acto médico, con plena consciencia y con conocimiento informado, o si la modifica formalmente, art. 7.

\footnotetext{
31 "Mediante la manifestación anticipada de voluntad una persona mayor de edad y capaz deja constancia en un documento escrito de las instrucciones emitidas libremente sobre los cuidados y el tratamiento de su salud o, una vez fallecida, el destino de su cuerpo y de sus órganos o tejidos, que deberán tenerse en cuenta cuando se encuentre en una situación cuyas circunstancias no le permitan expresar su voluntad de manera libre, personal, actual, consciente e informada".
} 
En cualquier caso, el art. 8 dispone que la manifestación anticipada de voluntad podrá ser modificada, sustituida y revocada libremente por el autor, siempre que se realice con los requisitos de capacidad, formales y procedimiento exigidos para el otorgamiento. También se podrá modificar una parte, estableciéndose expresamente, manteniéndose subsistentes las demás. Si se revoca el documento y no se sustituye se procederá a la baja registral del mismo.

Las funciones del Registro se recogen en el art. 11, fundamentalmente de inscripción, custodia, actualización, garantía de acceso a las personas autorizadas, coordinación y difusión sobre este derecho.

En el art. 12 se disponen los requisitos para la inscripción. En primer lugar, la norma señala que si la declaración se realiza ante Notario, la inscripción es voluntaria. $\mathrm{Si}$ se otorga ante el funcionario responsable del Registro, deberá ser inscrita ese mismo día o en caso de desplazamiento al domicilio del autor, en el plazo máximo de tres días. Cuando se realicen ante testigos, sólo serán válidas las inscritas en el Registro.

Podrán acceder al Registro el otorgante y el representante designado en la declaración así como el personal autorizado determinado por las autoridades sanitarias de la Comunidad Autónoma, "a través de comunicación telemática mediante el procedimiento de firma electrónica y código personal que se determine y que garantizará la identidad de la persona destinataria de la información, la integridad de la información a la que se accede y la constancia del acceso". El acceso al citado órgano se garantizará las 24 horas al día por lo que se establecerá un procedimiento alternativo al telemático para asegurar su accesibilidad.

\subsection{Comunidad Autónoma de Cantabria}

\subsubsection{La Ley 7/2002, de 10 de diciembre, de Ordenación Sanitaria de Cantabria $^{32}$}

Esta norma dedica su art. 34 a la regulación de la expresión de la voluntad con carácter previo. Podrán otorgarla los mayores de edad con plena capacidad de obrar y se aplicará en los supuestos en que no sea posible emitir su voluntad de manera personal, actual y consciente.

Los requisitos y procedimiento para su formalización han sido modificados por el art. 15.1 de la Ley 6/ 2009, de 28 de diciembre, Ley de Medidas de Cantabria de $2010^{33}$. Según lo dispuesto en el mismo, debe constar por escrito y formalizarse por alguno de los siguientes procedimientos: a- ante notario, no siendo precisa la presencia de testigos, b- ante tres testigos mayores de edad y con plena capacidad de obrar. Dos de ellos, como mínimo, no pueden tener con el otorgante relación de parentesco hasta el segundo grado, ni estar unidos por matrimonio ni relación análoga de afectividad conyugal. Tampoco puede existir ningún tipo de relación laboral, patrimonial o de servicio, c- ante

\footnotetext{
${ }^{32}$ B.O. Cantabria n. 242, 18 de diciembre de 2002, p. 10973; B.O.E. n. 6, 7 de enero de 2003, p. 551.

${ }^{33}$ B.O. Cantabria n. 25, 30 de diciembre 2009, p. 1273]; rect. B.O. Cantabria n. 21, 2 de febrero de 2010; B.O.E. n. 18, 21 de enero de 2010, p. 5936.
} 
los funcionarios de la Consejería competente en materia de sanidad designados reglamentariamente para tal función.

La citada Consejería pondrá a disposición del usuario un documento tipo que incluirá la posibilidad de rechazar los procedimientos de soporte vital, la sedación y/o analgesia en los casos terminales, los tratamientos que prolonguen temporal y artificialmente su vida y la designación de representantes. Tras su redacción se incorporará a la historia clínica del paciente. Estas declaraciones serán vinculantes tras su inscripción en el Registro correspondiente adscrito a la Consejería competente en materia de salud, recogiéndose su regulación en el texto legal que se expone a continuación.

No tendrán validez aquellas estipulaciones contrarias al ordenamiento jurídico, a la buena práctica médica ni las que no se correspondan exactamente con el supuesto de hecho previsto por el sujeto en el momento de emitirlas. En estos casos, se deberá realizar anotación motivada en la historia clínica del paciente.

\subsubsection{Decreto $139 / 2004$, de 5 de diciembre, por el que se crea y regula el Registro de Voluntades Previas de Cantabria ${ }^{34}$}

En relación a las funciones del Registro, el art. 4 señala las siguientes: inscripción, recopilación y custodia, coordinación con el Registro Nacional de Instrucciones Previas, garantía de acceso a las personas autorizadas.

Respecto a la presentación para su inscripción, deberá realizarse por el otorgante; si se otorgó ante tres testigos, deberá presentar el documento original y compulsa de los D.N.I. del otorgante y los testigos. Si se formalizó notarialmente, tendrá que presentarse copia autenticada, acompañada de un escrito de solicitud de inscripción en el Registro, art. 3 .

Por último, podrán acceder al Registro el autor de la declaración y su representante legal. En los supuestos en que el otorgante no pueda manifestar su voluntad, el personal que le prestare asistencia deberá solicitar al Registro información sobre la existencia o no del documento de voluntades expresadas con carácter previo y conocer su contenido, con independencia que conste o no una copia en su historia clínica. El acceso se realizará por medios telemáticos para garantizar la confidencialidad de los datos e información suministrada así como de la identidad de los solicitantes, siendo la disponibilidad de comunicación permanente. Todas las personas que por motivos laborales accedan a cualquier dato del Registro, deben guardar secreto sobre los mismos fuera de su ámbito de actuación, art. 4.

\subsection{Comunidad Autónoma de Castilla La Mancha}

\footnotetext{
${ }^{34}$ B.O. Cantabria n. 248, 27 de diciembre de 2004, p. 12419.
} 
2.7.1. Ley 6/2005, de 7 de julio, sobre la Declaración de Voluntades Anticipadas en materia de la propia salud de la Comunidad Autónoma de Castilla La Mancha ${ }^{35}$

Consta de 10 artículos, 1 Disposición Adicional y 2 Disposiciones Finales.

Se señala en el primer artículo el objeto de la norma y en el segundo se procede a la definición de la declaración de voluntad anticipada ${ }^{36}$.

Según lo dispuesto en el art. 3, puede emitirla cualquier persona mayor de edad que actúe libremente y no se encuentre incapacitada judicialmente para su emisión. En relación a su contenido, el art. 4 determina que se pueden incluir indicaciones respecto a los cuidados y tratamientos respecto a la salud que desee o no recibir y la decisión sobre el destino del cuerpo y los órganos tras el fallecimiento. Asimismo, se podrá designar a un representante que será el interlocutor con el personal facultativo para que se cumplan las instrucciones contenidas en el citado documento, debiendo constar por escrito su aceptación. Se exige que sea mayor de edad y que no esté incapacitado legalmente para el nombramiento, no pudiendo asumir esta función los siguientes sujetos: "a) El notario ante el que se formule la declaración, b) El personal del Registro de Voluntades Anticipadas de Castilla-La Mancha, c) Los testigos ante los que se formalice el documento, d) El personal sanitario que deba aplicar las voluntades anticipadas, e) Los gestores o propietarios de instituciones que financien o presten la atención sanitaria del otorgante de la declaración”.

La formalización del documento de la declaración de voluntades anticipadas podrá realizarse, art. 5:a-ante notario, b-ante un funcionario del Registro de Voluntades Anticipadas de Castilla-La Mancha, que esté habilitado para ello de acuerdo con su Reglamento, c- ante tres testigos, que deberán ser mayores de edad y con plena capacidad de obrar. Dos de ellos, como mínimo, no podrán estar vinculados con el otorgante por parentesco hasta el tercer grado de consanguinidad o afinidad, ni por matrimonio ni por relación profesional o patrimonial alguna.

Una vez formalizado, se podrá inscribir en el Registro de Voluntades Anticipadas de Castilla- La Mancha mediante entrega por el interesado, por su representante o por remisión notarial de copia autorizada a petición del otorgante.

Los requisitos de la declaración se contemplan en el art. 6 y hacen referencia a los datos de identidad del otorgante, funcionarios y testigos y, en su caso, del representante: nombre, apellidos, domicilio, número del D.N.I. o documento equivalente. Se debe incluir también la identificación que del autor han hecho los testigos o funcionario, lugar, fecha y hora en que se firma y la firma del declarante, funcionarios, testigos y

\footnotetext{
${ }^{35}$ D.O. Castilla-La Mancha n. 141, 15 de julio de 2005, p. 13757; B.O.E. n. 203, 25 de agosto de 2005, p. 29509.

36 "A los efectos de esta Ley, se entiende por declaración de voluntades anticipadas la manifestación escrita de una persona capaz que, actuando libremente, expresa las instrucciones que deban tenerse en cuenta sobre la asistencia sanitaria que desea recibir en situaciones que le impidan expresar personalmente su voluntad, o sobre el destino de su cuerpo o sus órganos una vez producido el fallecimiento".
} 
representante. El documento otorgado ante notario se formalizará conforme a lo establecido en la legislación notarial.

Este documento puede ser modificado, sustituido y revocado en cualquier momento conforme a lo estipulado en los artículos anteriores para su otorgamiento siendo válido, en cualquier caso, el último otorgado, art. 7.

En referencia a su eficacia, dispone el art. 8 que obligará a todo el personal sanitario a ejecutar lo recogido en el mismo, prevaleciendo sobre las opiniones e indicaciones que puedan realizar los familiares, allegados o representante y del propio estamento médico. En los supuestos en que una persona se encuentre imposibilitada para tomar decisiones por sí misma, los facultativos deben consultar si existe en el Registro la declaración de voluntades anticipadas y en caso afirmativo actuar conforme a lo establecido en la misma. Por último, se señala que no tendrán validez las instrucciones contrarias al orden público, a la buena práctica médica ni las que no correspondan con el supuesto de hecho que el interesado haya previsto en el momento de manifestarlas debiendo, en estos casos, realizar anotación motivada en la historia clínica del paciente.

En el art. 8 se establece la creación del Registro Autonómico de Voluntades Anticipadas.

La comunicación de las voluntades anticipadas al personal facultativo puede realizarse mediante la remisión del documento por parte del Registro al centro donde el otorgante sea atendido, sin perjuicio que pueda ser entregado por el mismo declarante o si se encuentra imposibilitado, por su representante, familiares, representante legal o cualquier otra persona que lo tuviese en su poder, según consta en el art. 9.

\subsubsection{Decreto 15/2006, de 21 de febrero, del Registro de Voluntades Anticipadas de Castilla La Mancha ${ }^{37}$}

Las funciones del Registro se especifican en el art. 2; básicamente se refieren la inscripción, custodia, garantía de acceso a las personas autorizadas, coordinación con el Registro Nacional de Instrucciones Previas.

La presentación para su inscripción se realizará por el otorgante. Si se formalizó ante Notario, se requerirá fotocopia del D.N.I., pasaporte o cualquier documento oficial que acredite su identidad y la copia autorizada del documento otorgada ante Notario. Si se ha realizado ante testigos, se exige la presentación de la fotocopia del D.N.I., pasaporte o cualquier documento oficial que acredite su identidad del autor y de los testigos. En caso de otorgarse ante funcionario del Registro, la fotocopia del D.N.I., pasaporte o cualquier documento oficial que acredite su identidad y el documento de voluntades anticipadas, cumplimentado según modelo recogido Anexo II., art. 4.

Pueden acceder al mismo, el autor, su representante que conste en el documento, en su caso, el representante legal del otorgante y los profesionales sanitarios que le presten asistencia, art. 7.

\footnotetext{
${ }^{37}$ D.O. Castilla-La Mancha n. 42, 24 de febrero de 2006, p. 4429.
} 


\subsection{Comunidad Autónoma de Castilla y León}

\subsubsection{Ley $8 / 2003$, de 8 de abril, sobre derechos y deberes de las personas en relación con la salud de la Comunidad Autónoma de Castilla y León ${ }^{38}$}

Se exige el respeto a las instrucciones previas sobre la propia salud, cuando el paciente no puede expresarlas de forma personal, art. 30. Sólo podrán ser realizadas por personas mayores de edad y que actúen libremente. Los procedimientos de formalización son los siguientes: a-ante notario, no siendo necesaria la presencia de testigos, b-ante personal al servicio de la Administración designada por la Consejería competente en materia de salud en las condiciones establecidas reglamentariamente, cante tres testigos mayores de edad y con plena capacidad de obrar. Dos de ellos, como mínimo, no podrán tener relación de parentesco hasta el segundo grado ni estar vinculados por relación patrimonial u otro vínculo obligacional con el otorgante.

\subsubsection{Decreto 30/2007, de 22 de marzo, que regula el documento de Instrucciones Previas en el ámbito sanitario de Castilla y León ${ }^{39}$}

Este Decreto desarrolla normativamente la citada Ley.

En el art. 2 se establece su definición ${ }^{40}$. En relación al contenido, el autor puede realizar previsiones sobre las instrucciones sobre los cuidados y el tratamiento de su salud, el destino de su cuerpo o de sus órganos una vez llegado el fallecimiento, manifestaciones para que se evite el sufrimiento con medidas paliativas y, en su caso, para que no se prolongue la vida artificialmente por medio de tecnologías y tratamientos desproporcionados o extraordinarios, según lo establecido en el art. 3.

Conforme a lo dispuesto en el art. 6, puede actuar como representante cualquier persona mayor de edad que no se encuentre incapacitada, con las siguientes excepciones: notario o testigos ante los que se formalizó el documento, el responsable del Registro, el personal de las compañías que financien la atención sanitaria del otorgante y el personal sanitario que debe aplicar las instrucciones previas.

La finalidad del Registro se establece en el art. 11: inscripción, custodia, garantía de acceso a las personas autorizadas, coordinación con el Registro Nacional de Instrucciones Previas y difusión sobre este derecho.

\footnotetext{
${ }^{38}$ B. O. Castilla y León n. 71, 14 de abril de 2003, p. 6; B.O.E. n. 103, 30 de abril de 2003, p. 16650.

${ }^{39}$ B.O. Castilla y León n. 62, 28 de mayo de 2007, p. 7040.

${ }^{40 " L a s}$ instrucciones previas son la manifestación anticipada de voluntad que hace por escrito cualquier persona mayor de edad, capaz y libre, acerca de los cuidados y el tratamiento de su salud o sobre el destino de su cuerpo o de sus órganos una vez llegado el fallecimiento, para que sea tenida en cuenta, por el médico o por el equipo sanitario responsable de su asistencia, en el momento en que se encuentre en una situación en que las circunstancias que concurren le impidan expresarla por sí misma".
} 
La solicitud de la inscripción la realizará el otorgante, art. 16. Las personas legitimadas para acceder al Registro son recogidas en el art. 21: otorgante, su representante, médico responsable de la asistencia médica tanto de centros de titularidad pública como privada. Se hará por medidos telemáticos para garantizar la confidencialidad de la información suministrada y de la identidad del solicitante.

\subsection{Comunidad Autónoma de Cataluña}

2.9.1. Ley $21 / 2000$, de 29 de diciembre, sobre los derechos de información relativos a la salud, la autonomía del paciente y la documentación clínica de la Comunidad Autónoma de Cataluña ${ }^{41}$

Esta norma fue pionera en nuestro ordenamiento jurídico en la regulación de esta materia.

El art. 8 de la citada norma regula el documento de voluntades anticipadas ${ }^{42}$.

Puede ser formalizado mediante alguno de los siguientes procedimientos: a- ante notario, no precisando la presencia de testigos, $b$ - ante tres testigos mayores de edad y con plena capacidad de obrar, no pudiendo, al menos dos de ellos, tener relación de parentesco hasta el segundo grado ni estar vinculados por relación patrimonial con el otorgante.

Se tendrán por no puestas las voluntades anticipadas que sean contrarias al ordenamiento jurídico, a la buena práctica clínica o que no se correspondan exactamente con el supuesto de hecho previsto por el sujeto en el momento de otorgarlas. En estos casos, deberá hacerse anotación razonada en la historia clínica del paciente.

Las voluntades anticipadas han de ser entregadas al centro sanitario donde la persona sea atendida, bien por el otorgante, sus familiares o el representante, debiendo incluirse el citado documento en la historia clínica del paciente.

\subsubsection{Decreto $175 / 2002$, de 25 de junio, sobre el Registro de Voluntades Anticipadas en Cataluña ${ }^{43}$}

${ }^{41}$ D.O. Generalitat de Catalunya n. 3303, 11 de enero de 2001, p. 464; rect. D.O. Generalitat de Catalunya n. 3353, 22 de marzo de 2001, p. 4211] (castellano); D.O. Generalitat de Catalunya n. 3353, 22 de marzo de 2001, p. 4211(catalán); B.O.E. n. 29, 2 de febrero de 2001, p. 4121.

42 "El documento de voluntades anticipadas es el documento, dirigido al médico responsable, en el cual una persona mayor de edad, con capacidad suficiente y libremente, expresa las instrucciones a tener en cuenta cuando se encuentre en una situación en que las circunstancias que concurran no le permitan expresar personalmente su voluntad. En este documento, la persona puede también designar a un representante, que es el interlocutor válido y necesario con el médico o el equipo sanitario, para que la sustituya en el caso de que no pueda expresar su voluntad por sí misma".

${ }^{43}$ D.O. Generalitat de Catalunya n. 3665, 27 de junio de 2002, p. 11616. 
Respecto a su a su inscripción, es preciso señalar que se inicia mediante solicitud del otorgante del documento. Si se ha emitido ante testigos, se presentará el original junto al escrito de solicitud establecido en anexo 1 del Decreto. También, deberá adjuntarse una copia compulsada del documento nacional de identidad o del pasaporte, en vigor, de la persona otorgante y de cada una de las personas que hayan actuado de testigos. En el supuesto de su otorgamiento ante notario, debe presentarse una copia autenticada, acompañada de un escrito de solicitud de inscripción registral.

El art. 5 dedicado a la regulación del fichero automatizado, ha sido derogado por la disposición derogativa_de la Orden n. 519/2006, de 3 de noviembre, que regula ficheros que contienen datos de carácter personal en el ámbito del Departamento de Salud $^{44}$.

En relación a su acceso, el art. 6 legitima al propio paciente, familiares, representante y al médico responsable de su asistencia.

2.10. Ciudades Autónomas de Ceuta y Melilla

En las Ciudades Autónomas de Ceuta y Melilla se aplica la Ley 41/2002, de 14 de noviembre, básica reguladora de la autonomía del paciente y de derechos y obligaciones en materia de información y documentación clínica. Respecto al Registro de Instrucciones Previas, el Real Decreto 124/2007, de 2 de febrero, por el que se regula el Registro nacional de instrucciones previas y el correspondiente fichero automatizado de datos de carácter personal, dispone su extensión a las citadas Ciudades en su Disposición Adicional 2a.

\subsection{Comunidad Autónoma de Extremadura}

\subsubsection{Ley $3 / 2005$, de 8 de julio, de información sanitaria y autonomía del paciente de la Comunidad Autónoma de Extremadura ${ }^{45}$}

Se dedica el II capítulo del Título IV de la citada norma a la regulación de la denominada expresión anticipada de voluntades. En el art. 17 se recoge su concepto ${ }^{46}$.

\footnotetext{
${ }^{44}$ D.O. Generalitat de Catalunya n. 4758, 10 de noviembre de 2006, p. 47162.

${ }^{45}$ D. O. Extremadura n. 82, 16 de julio de 2005, p. 10442; B.O.E. n. 186, 8 de agosto de 2005, p. 27513.

46 "La expresión anticipada de voluntades es el documento emitido por una persona mayor de edad, con capacidad legal suficiente y libremente, dirigido al médico responsable de su asistencia, en el cual expresa las instrucciones sobre sus objetivos vitales, valores personales y las actuaciones médicas que deberán ser respetados cuando se encuentre en una situación en que las circunstancias que concurran no le permitan expresar personalmente su voluntad.

La expresión de los objetivos vitales y valores personales tiene como fin ayudar a interpretar las instrucciones y servir de orientación para la toma de decisiones clínicas llegado el momento.

Las instrucciones sobre las actuaciones médicas pueden referirse tanto a una enfermedad o lesión que la persona otorgante ya padece como a las que eventualmente puede sufrir en el futuro, e incluir previsiones relativas a las intervenciones médicas acordes con la buena práctica clínica que desea recibir, a las que no desea recibir y a otras cuestiones relacionadas con el final de la vida”.
} 
Puede nombrarse también como interlocutor válido con el personal facultativo a un representante. Asimismo, en el documento se pueden incluir disposiciones respecto a la donación de órganos con fines terapéuticos, docentes o de investigación. En cuanto a los modos de formalización, la norma dispone que se podrá realizar: a- ante notario, bante tres testigos mayores de edad y con plena capacidad de obrar, de los cuales dos, como mínimo, no deben tener relación de parentesco hasta el segundo grado ni estar vinculados por relación matrimonial, de hecho o patrimonial con el otorgante.

El documento puede ser entregado en el Registro de Expresión Anticipada de Voluntades de la CCAA de Extremadura por el interesado, representante legal o familiares, o bien entregarse en el centro sanitario donde la persona sea atendida o al médico responsable de la asistencia, quienes realizarán las actuaciones necesarias para su remisión al citado Registro, recibiendo el inscribiente certificación acreditativa de su inscripción.

Los datos que debe contener son de distinta naturaleza, de una parte, formales: el nombre y apellidos del declarante, número de D.N.I., pasaporte o permiso de residencia, domicilio, en su caso, designación del representante indicando su nombre, apellidos, número D.N.I. y firma., lugar y fecha del otorgamiento y firma del otorgante. Por otro lado, se debe especificar cuestiones relativas al momento y modo de aplicación del documento: "Situaciones sanitarias concretas en que se quiere que se tengan en cuenta las instrucciones, instrucciones y límites concretos en la actuación médica ante decisiones previstas, sobre todo cuando se tiene información de probabilidades evolutivas y otras consideraciones, como objetivos vitales, valores personales, decisiones sobre la donación de órganos, etcétera”

En el art. 19 se contempla la posibilidad de que el documento sea modificado, revocado o sustituido, siempre que concurran los requisitos establecidos en los artículos anteriores para su otorgamiento. Tendrá validez el otorgado en último lugar.

Son diversas las obligaciones del equipo médico en materia de voluntades anticipadas, como recoge el art. 20, entre otras: aceptar los documentos, respetar su contenido, informar a los pacientes sobre el mismo...

En tanto la persona conserve su capacidad, prevalecerá su opinión sobre lo estipulado en el documento de voluntades anticipadas, perdiendo eficacia las instrucciones previas si el paciente emite un consentimiento informado ante un determinado tratamiento terapéutico que contraríe las mismas, aplicándose lo contenido en aquél si se encuentra en situación de no poder expresar su opinión. Se tendrán por no puestas las estipulaciones contrarias a la ley, a la buena práctica clínica y aquellas que no se correspondan exactamente con el supuesto de hecho contemplado en el documento, sin hacer mención a la buena práctica o "lex artis". En estos casos, será procedente la anotación motivada en la historia clínica del paciente, art. 21.

En el art. 22 se dispone la creación del Registro de voluntades anticipadas de la CCAA de Extremadura.

2.11.2. Decreto 311/2007, de 15 de octubre, por el que se regula el contenido, la organización y el funcionamiento del Registro de Expresión anticipada de 


\section{Voluntades de la Comunidad Autónoma de Extremadura y se crea el Fichero Automatizado de datos de carácter personal del citado Registro ${ }^{47}$.}

Las funciones del Registro son, entre otras, las siguientes: inscripción, custodia, actualización, garantía de acceso a las personas autorizadas, información a los interesados sobre este documento, comprobación de los requisitos de validez, expedir certificaciones..., art. 6

La solicitud para su inscripción deberá realizarse por el otorgante, representante legal y familiares que actúen en su representación, art. 8. Podrán acceder al mismo el otorgante, el representante designado en el documento, el representante legal en su caso y todos los profesionales sanitarios que le presten asistencia sanitaria. Además, el Registro debe poner en conocimiento de los profesionales de la sanidad que ejerzan en centros sanitarios públicos o privados la existencia del citado documento. Garantiza su acceso en situaciones de emergencia interconectando el teléfono de urgencias 112 con el Registro, art. 14.

\subsection{Comunidad Autónoma de Galicia}

2.12.1. Ley $3 / 2001$, de 28 de mayo, reguladora del consentimiento informado y de la historia clínica de los pacientes ${ }^{48}$ modificada por la Ley $3 / 2005$, de 7 de marzo de Galicia $^{49}$

Mediante el apartado tercero del artículo único de la citada norma, se procede a la modificación del art. 5 de la Ley $3 / 2001^{50}$. Los cambios afectan a la expresión utilizada «voluntades anticipadas» por la de «instrucciones previas» e introducen variaciones en los distintos apartados del artículo añadiéndose dos nuevos puntos al mismo.

No se aplicarán las instrucciones previas contrarias al ordenamiento jurídico, al articulado de la ley, ni las que no se correspondan con el supuesto de hecho que el interesado tenga previsto en el momento de manifestarlas. En la historia clínica del paciente quedará constancia razonada de las anotaciones relacionadas con estas previsiones.

Deberá formalizarse bien ante notario o ante tres testigos mayores de edad con plena capacidad de obrar, de los cuales dos, como mínimo, no podrán tener relación de parentesco, hasta el segundo grado ni estar vinculados por cualquier relación patrimonial con el otorgante.

\footnotetext{
${ }^{47}$ D.O. Extremadura n. 121, 18 de octubre de 2007, p. 16210.

${ }^{48}$ DO. Galicia n. 111, 8 de junio de 2001, p. 7593; B.O.E. n. 158, 3 de julio de 2001, p. 23537.

${ }_{50}^{49}$ D.O. Galicia n. 55, 21 de marzo de 2005, p. 4760.

50 "Por el documento de instrucciones previas, una persona mayor de edad, capaz y libre, manifiesta anticipadamente su voluntad, a fin de que ésta sea cumplida en el momento en que llegue a situaciones en las que por las circunstancias no sea capaz de expresarla personalmente, sobre los cuidados y el tratamiento de su salud, o, una vez llegado el fallecimiento, sobre el destino de su cuerpo o de los órganos del mismo. El otorgante del documento puede designar, además un representante para que, llegado el caso, sirva como interlocutor suyo con el médico o el equipo sanitario para procurar el cumplimiento de las instrucciones previas".
} 
Podrán ser revocadas en cualquier momento, debiendo constar por escrito. Se estipula la creación de un Registro Autonómico de Instrucciones Previas adscrito a la Consellería de Sanidad, que se regirá por las normas reglamentarias estipuladas al efecto.

2.12.2. Decreto 159/2014, de 11 de diciembre, que establece la organización y funcionamiento del Registro gallego de Instrucciones Previas sobre cuidados y tratamiento de la salud ${ }^{51}$.

En el art. 4 se explicitan las funciones del Registro, entre otras, inscripción y custodia de los documentos, comunicación a los centros sanitarios de la existencia de estos documentos y transmisión de su contenido a las personas legitimadas para su acceso.

Respecto al contenido de las Instrucciones previas, el art. 5 declara que podrán incluirse: "a) Instrucciones y opciones acerca de los cuidados y el tratamiento de la salud de la persona otorgante. b) Instrucciones sobre el destino del cuerpo, una vez llegado el fallecimiento, en relación con la donación de órganos y tejidos para trasplante o con la donación para docencia e investigación científica”. Se recoge también la posibilidad de nombrar un representante.

El art. 6 recoge las posibles formas, por escrito, de formalización del documento: " $a$ - ante notario/a, sin necesidad de la presencia de testigos. $b$ - ante tres testigos mayores de edad y con plena capacidad de obrar, de los cuales dos, como mínimo, no podrán tener relación de parentesco hasta el segundo grado por consanguinidad o afinidad ni estar vinculados por matrimonio o análoga relación de afectividad ni por relación patrimonial ${ }^{52}$ con la persona otorgante. c-ante el personal del Registro gallego de instrucciones previas o de las unidades habilitadas".

Cabe su modificación, ampliación, concreción o revocación en cualquier momento por el otorgante, siempre que conserve su capacidad, dejando constancia expresa e indubitada, conforme al art. 7.

La solicitud para su inscripción será realizada por el declarante o por su representante legal, cumpliendo los requisitos establecidos en el art. 8 y aportando la documentación pertinente.

En relación a las personas legitimadas para acceder al contenido del Registro, el art. 10 establece las siguientes: el otorgante, su representante legal o el designando como interlocutor con el facultativo. Asimismo, cuando el paciente no pueda expresar por sí mismo su voluntad, el médico que le presta asistencia sanitaria deberá acceder, de forma telemática, al Registro para comprobar la existencia del documento de instrucciones previas.

\footnotetext{
${ }^{51}$ D.O. Galicia, n. 248, 29 de diciembre de 2014, p. 52759.

52 "Hay relación patrimonial cuando exista entre ambos créditos o deudas, pertenencia en común de bienes muebles o inmuebles, titularidad conjunta de una entidad profesional, explotación mercantil o industrial o, en general, cualquier otro vínculo obligacional de naturaleza económica".
} 
Por último, el art. 15 dispone la obligación por parte de los profesionales sanitarios "de respetar y aplicar las instrucciones previas en los términos legalmente previstos y de dejar constancia en la historia clínica de su aplicación. Asimismo, deben dejar constancia motivada en la historia clínica de la no aplicación de las instrucciones previas cuando sean contrarias al ordenamiento jurídico o a la lex artis, o no se correspondan con el supuesto de hecho que la persona otorgante haya previsto en el momento de manifestarlas”.

\subsection{Comunidad Autónoma de La Rioja}

\subsubsection{Ley 9/2005, de 30 de septiembre, reguladora del documento de instrucciones previas en el ámbito de la sanidad de la Comunidad Autónoma de La Rioja $^{53}$}

Se estructura en 11 artículos, 2 Disposiciones Adicionales, 1 Disposición Derogatoria y 4 Disposiciones Finales.

En el art. $1^{\circ}$ se establece el objeto de la norma y en el $2^{\circ}$ se determina que el ámbito de aplicación se circunscribe a la Comunidad Autónoma de La Rioja. En el art. 3 se recoge su definición ${ }^{54}$.

La capacidad exigida para otorgar un documento de instrucciones previas es ser mayor de edad, no estar incapacitado judicialmente y actuar de forma libre, como reza el art. 4.

En relación al contenido de este documento, se recogen en el art. 5 las múltiples estipulaciones que se pueden incluir ${ }^{55}$.

\footnotetext{
${ }_{54}^{53}$ B.O. La Rioja n. 133, 6 de octubre de 2005, p. 5587; B.O.E. n. 252, 21 de octubre de 2005, p. 34392.

54 "El documento de instrucciones previas es aquel que contiene la declaración de voluntad de una persona sobre los cuidados y el tratamiento de su salud, para que ésta se cumpla en el momento en que no sea capaz de expresarla personalmente. Asimismo, el documento podrá contener la declaración de voluntad sobre el destino del propio cuerpo o de los órganos del mismo, una vez producido el fallecimiento.
}

El documento de instrucciones previas supone la culminación de un proceso de planificación, una vez que el otorgante se ha informado, reflexionado y comunicado sus preferencias de cuidados y tratamientos, sobre todo los relativos al final de su vida, a su representante y seres queridos. El documento válidamente emitido es un instrumento que podrá utilizarse en la toma de decisiones clínicas".

55 "A. La expresión de objetivos vitales, calidad de vida y expectativas personales; así como las opciones personales en cuanto a valores éticos, morales, culturales, sociales, filosóficos o religiosos.

B. Las situaciones del declarante relativas a su estado de salud en las que habrá de recurrirse a las instrucciones otorgadas, ya se trate de una enfermedad o lesión que el otorgante padece, ya se trate de las que relacionadas de forma concreta pudiera padecer en el futuro.

C. Los cuidados o el tratamiento a los que quiere o no quiere someterse en los casos anteriormente expresados, de entre los que con carácter enunciativo se señalan los siguientes:a) Que se agoten los tratamientos indicados sobre sus dolencias, siempre que no sean desproporcionados en su aplicación o en relación a su previsible resultado. b) Su voluntad contraria a recibir tratamiento de soporte vital; o interrumpir el ya iniciado, cuando éste sea inefectivo para la satisfacción de determinados valores o para mantener una adecuada calidad de vida. c) Su voluntad contraria a que se prolongue temporal y artificialmente la vida si no se acompaña de ningún resultado aceptable para los objetivos del 
Referente a su formalización, el art. 5 estipula que se deberá realizar por escrito, constando en el mismo lugar y fecha de otorgamiento, identificación del declarante y su firma. Si se formaliza ante testigos, deberán también ser identificados y figurar su firma.

El modo de formalización puede ser: a- ante notario, b- ante tres testigos debidamente identificados, mayores de edad y que no se encuentren incapacitados judicialmente. Al menos dos de ellos no podrán tener relación de parentesco con el otorgante hasta el segundo grado de consanguinidad o afinidad, ni existir vínculo matrimonial ni relación afectiva análoga ni patrimonial, c- ante el personal al servicio de la Administración General de la CCAA de La Rioja o de sus Organismos Autónomos en la forma establecida mediante Orden dictada por el Consejero competente en materia de salud.

El documento será eficaz cuando el sujeto no pueda emitir su voluntad, por lo que mientras conserve su capacidad prevalecerá su opinión sobre lo establecido en el mismo. Puede ser revocado, sustituido o modificado, siendo válido el emitido en último lugar. Se garantizará por Administración sanitaria el cumplimiento de su contenido, dentro de los límites de la norma. En el supuesto de objeción de conciencia de un facultativo, se proveerán los recursos necesarios para cumplir la voluntad del otorgante. En las historias clínicas podrán constar si el paciente ha otorgado un documento de instrucciones previas, debiendo ser incorporados en el momento en que deban surtir efectos, art. 6.

Considera la Ley en su art. 8 que dado que es muy difícil que el declarante pueda prever anticipadamente todas sus contingencias futuras, el documento deberá ser interpretado en el contexto clínico real del caso. En el supuesto de discrepancias entre el representante y el personal facultativo, se solicitará la mediación de un Comité Ético.

otorgante. d) Su deseo de que se utilicen los procedimientos de sedación y analgesia necesarios para evitar el dolor y el sufrimiento. $D$. La designación de uno o varios representantes, con facultades para tomar decisiones en lugar del otorgante, actuar de interlocutor con el médico o equipo sanitario $e$ interpretar el documento, todo ello dentro de los límites contenidos en el propio documento. Los representantes deberán estar debidamente identificados, ser mayores de 18 años, no estar incapacitados y aceptar la designación. Dentro de los límites señalados en el párrafo anterior, la actuación del representante estará orientada a hacer valer lo que el otorgante hubiera preferido en el caso de que pudiera decidir. De no conocer la que hubiera sido su voluntad, la actuación del representante estará orientada a hacer valer todo cuanto contribuya a los mejores intereses del otorgante. En el caso de designar varios representantes, se deberá indicar si éstos actuarán de forma sucesiva o simultánea; y en este último caso, si lo harán mancomunada o solidariamente. No podrán actuar como representantes el notario autorizante del documento, los testigos ante quienes se hubiera formalizado, el funcionario encargado del Registro de Instrucciones Previas de La Rioja, ni los profesionales que hayan de aplicar las instrucciones previas. E. Instrucciones sobre el destino de su cuerpo, así como de los órganos del mismo, una vez llegado el fallecimiento, de acuerdo con lo establecido en la legislación específica. 2. Se tendrán por no puestas, y por tanto no serán aplicadas, las instrucciones que sean contrarias al ordenamiento jurídico, a la «lex artis» o a la buena práctica clínica. Tampoco se aplicarán las instrucciones que no se correspondan con el supuesto de hecho que el otorgante haya previsto en el momento de manifestarlas; ni las que resulten contraindicadas para su patología. Todos estos supuestos deberán anotarse de forma motivada en la historia clínica". 
Se contempla en el art. 9, la posibilidad de que el otorgante amplíe, modifique, revoque, sustituya el contenido del documento, pudiendo además revocar o sustituir a los representantes o variar las condiciones de la representación siempre que se realice según lo establecido en los artículos precedentes. Los representantes podrán renunciar a su nombramiento en cualquier momento.

En el art 10 se dispone la creación del Registro de Instrucciones Previas.

2.13.2. Decreto 30/2006, de 19 de mayo, por el que se regula el Registro de Instrucciones Previas de La Rioja ${ }^{56}$. Posteriormente, se aprobó la Orden 8/2006, de 26 de julio, de la Consejería de Salud, sobre la forma de otorgar documento de instrucciones previas ante personal de la Administración ${ }^{57}$.

Impone el art. 11 el deber de secreto al personal de la Administración sobre el contenido de los documentos de instrucciones previas que tengan conocimiento en el ejercicio de sus funciones.

Las funciones del Registro se recogen en el art. 3 y básicamente son las siguientes: inscripción de los documentos de instrucciones previas, custodia de los mismos, comunicación a los centros sanitarios de la existencia de estos documentos y transmisión de su contenido al personal médico responsable.

La única persona legitimada para solicitar su inscripción es el otorgante, como dispone el art. 5.

Las personas legitimadas para acceder al Registro son el otorgante, el médico responsable de la asistencia, los representantes.

\subsection{Comunidad Autónoma de Madrid}

2.14.1. Ley 3/2005, de 23 de mayo, por la que se regula el ejercicio del derecho a formular instrucciones previas en el ámbito sanitario y se crea el registro correspondiente de la Comunidad Autónoma de Madrid $^{58}$

Consta la de 12 artículos, 1 Disposición Derogatoria y 3 Disposiciones Finales.

Se determina en el primer artículo el objeto de la presente norma y en el segundo el concepto de instrucciones previas ${ }^{59}$. El citado documento debe ser respetado por el equipo sanitario y cualquier persona que atienda al paciente. Se adoptarán los medios necesarios para el cumplimiento del mismo, sin perjuicio de que los facultativos puedan ejercer la objeción de conciencia para la aplicación de la voluntad recogida en las

\footnotetext{
${ }^{56}$ B.O. La Rioja n. 69, 25 de mayo de 2006, p. 3101.

${ }^{57}$ B.O. La Rioja n. 103, 5 de agosto de 2006, pp. 4760 (edición electrónica).

${ }^{58}$ B.O. Comunidad de Madrid n. 140, 14 de junio de 2005, p. 4; B.O.E. n. 269, de 10 de noviembre de 2005 , p. 36755.

59 "Por el documento de instrucciones previas, una persona manifiesta anticipadamente su voluntad, con objeto de que ésta se cumpla en el momento en que llegue a situaciones en cuyas circunstancias no sea capaz de expresarla personalmente, sobre el cuidado y el tratamiento de su salud o, llegado el momento del fallecimiento, sobre el destino de su cuerpo o de los órganos del mismo”.
} 
instrucciones previas, art. 3. Se exige que el otorgante sea mayor de edad, no esté incapacitado judicialmente y emita su voluntad de forma libre como se recoge en el art. 4.

En referencia a los requisitos de formalización, el art. 5 dispone que ha de constar por escrito, figurando en el mismo la identificación del declarante, firma, fecha y lugar del otorgamiento. Los procedimientos estipulados en la Ley son los siguientes: a- ante notario, sin requerirse presencia testigos, b- ante el personal al Servicio de la Administración, según se determine en la Orden del Consejero de Sanidad y Consumo que garantizará los mecanismos de formalización en todas las áreas sanitarias, c- ante tres testigos mayores de edad y con plena capacidad de obrar, no pudiendo, como mínimo dos de ellos, tener relación de parentesco hasta el segundo grado ni estar vinculados por matrimonio ni por relación análoga de afectividad, ni relación laboral, de servicio $\mathrm{u}$ otro vínculo obligacional con el otorgante, debiendo el funcionario correspondiente, de forma previa, a la inscripción en el Registro, comprobar estos requisitos.

En el art. 6 se recogen las estipulaciones que se pueden incluir en el documento: manifestaciones sobre cuidados y tratamientos, el destino de su cuerpo y órganos, declaraciones para evitar el sufrimiento con medidas paliativas, previsiones sobre las intervenciones médicas u otras cuestiones relacionadas con el final de la vida, siempre que sean conforme a la lex artis, no ser informados en los supuestos de diagnóstico fatal...

En tanto el otorgante cumpla los requisitos de capacidad y de formalización estipulados en la norma, el documento de instrucciones previas puede ser modificado, sustituido o revocado, siendo válido el otorgado en último lugar. En todo caso y mientras pueda manifestarse libremente, prevalecerá su voluntad a lo estipulado en el documento de instrucciones previas.

Los arts. 8 y 9 disponen que son destinatarios del citado documento, el médico que lo atiende de forma directa y cualquier otro profesional que pueda intervenir en la actuación sanitaria. El documento de instrucciones previas se incorporará a la historia cínica del paciente, haciéndose constar en un lugar visible al acceder a la misma. Se les exige el deber de secreto sobre su contenido, así como a cualquier otra persona que por razón de su oficio pueda tener acceso al mismo.

El declarante puede nombrar uno o más representantes, en el orden y en la forma que estime conveniente, que actuarán como interlocutores con el equipo médico para el cumplimiento de las instrucciones previas. El nombramiento se podrá realizar en el mismo documento de instrucciones previas o en otro distinto, cumpliendo en este último caso, los requisitos exigidos para la formalización del citado documento. Cualquier persona mayor de edad y con plena capacidad de obrar puede realizar esta función, con las siguientes excepciones: notario autorizante del documento, funcionario encargado del Registro de Instrucciones Previas, los testigos antes los que se formalice el documento y los profesionales del centro sanitario dónde hayan de aplicarse las instrucciones previas, art, 11.

No se aplicarán las instrucciones previas contrarias al ordenamiento jurídico, a la lex artis, las que no se correspondan con el supuesto de hecho que el interesado haya 
previsto en el momento de manifestarlas, ni las que resulten contraindicadas para su patología. En estos dos últimos supuestos, se dejará constancia razonada en la historia clínica mediante las anotaciones correspondientes. Se informará por escrito al paciente y a sus familiares si así lo solicitaran, como reza el art. 11 .

En el art. 12 se dispone la creación de un Registro de Instrucciones Previas de la Comunidad de Madrid adscrito a la Consejería de Sanidad y Consumo para la custodia, conservación y accesibilidad de los citados documentos.

2.14.2. Decreto 101/2006, de 16 de noviembre, del Consejo de Gobierno, por el que se regula el Registro de Instrucciones Previas de la Comunidad de Madrid ${ }^{60}$

Respecto a las funciones, el Registro desarrollará las siguientes, art. 4: inscripción, expedir certificaciones, garantizar el acceso, proporcionar información a los ciudadanos, coordinación con el Registro Nacional de Instrucciones Previas.

En el art. 5 del Decreto 101/2006 se determinan las personas legitimadas para el acceso al Registro: otorgante, cualquier persona con poder, médico encargado de la asistencia, testigos y representante del interlocutor.

Por último, podrán solicitar la inscripción el otorgante o persona con poder, art. 6 .

2.14.3. Orden 2191/2006, de 18 de diciembre, por el que se regula el Registro de Instrucciones Previas ${ }^{61}$

Establece requisitos de orden formal en relación a la inscripción de las Instrucciones Previas, como los modelos oficiales y condiciones en que debe realizarse, arts. 1 y 2 .

Dispone además, en su art. $3^{\circ}$, la posibilidad de revocación, modificación o sustitución de las mismas, siempre que esté en plenas facultades. No obstante, su voluntad ante cualquier actuación clínica, prevalecerá sobre lo estipulado en el citado documento.

\subsection{Comunidad Autónoma de Murcia}

2.15.1. Decreto 80/2005, 19 de julio, que aprueba el Reglamento de Instrucciones Previas y su Registro de la Comunidad Autónoma de Murcia ${ }^{62}$.

Se divide en dos capítulos, el primero de ellos dedicado a las Instrucciones Previas y el segundo a la regulación del Registro para la inscripción de las mismas, tres Disposiciones Adicionales y una Disposición Final.

\footnotetext{
${ }^{60}$ B.O. Comunidad de Madrid n. 283, 28 de noviembre de 2006, p. 37.

${ }^{61}$ B.O. Comunidad de Madrid n. 302, 20 de diciembre de 2006, p. 28.

${ }^{62}$ B.O. Región Murcia n. 167, 19 de julio de 2005, p. 17253.
} 
En el art. $1^{\circ}$ se dispone el objetivo de la norma y la misión de los profesionales sanitarios para la difusión e información a los pacientes sobre su derecho a redactar tal documento.

En relación a su contenido y formalización señala el art. 2 que deberá contener los siguientes extremos: identificación del otorgante, y en su caso, testigos y representantes, mediante nombre, apellidos, domicilio, número del documento nacional de identidad $\mathrm{u}$ equivalente. En relación a las instrucciones previas, se exige su constancia por escrito, mediante uno de los siguientes procedimientos: a- ante notario, conforme a la legislación notarial, b-ante funcionario o empleado público encargado del Registro de Instrucciones Previas de la Región de Murcia, no requiriéndose la presencia de testigos, pero sí la indicación del nombre y apellidos del empleado o funcionario actuante, c- tres testigos, mayores de edad y con plena capacidad de obrar, que declararán bajo su responsabilidad que el otorgante es mayor de edad, actúa libremente, sin constarles que esté incapacitado judicialmente y que ha firmado el documento en su presencia.

En el art. 3 se dispone que el declarante podrá nombrar un representante, mayor de edad y no incapacitado legalmente, como interlocutor válido y necesario de los valores e instrucciones contenidos en el documento con el equipo médico cuando él no pueda manifestar libremente su voluntad. Su interpretación deberá ser adecuada a las circunstancias y proporcionada a las necesidades existentes, siempre a favor del otorgante y con respeto a su dignidad como persona.

El documento de instrucciones previas puede ser modificado, sustituido o revocado en cualquier momento por el otorgante, siempre que conserve la capacidad y otorgue un nuevo documento de instrucciones previas utilizando la misma forma documental utilizada para su otorgamiento.

El nuevo documento deberá contener además los siguientes requisitos: identificación del documento al que afecta, mediante la expresión del lugar y día del otorgamiento, notario, funcionario, empleado público o testigos ante los que se formalizó.

En función de su naturaleza modificativa, sustitutiva o revocatoria, se dispone lo siguiente:

En el primer supuesto, se debe expresar con total claridad qué parte del documento previo permanece vigente, cuál queda sin efectos y la nueva redacción, en su caso, de la parte incorporada. En el segundo, la declaración del otorgante de sustituir dicho documento, estableciendo las nuevas instrucciones previas y por último, la decisión de revocar íntegramente el documento y por tanto, dejarlo sin efectos. En todos los casos, deberá constar el lugar, fecha de modificación, sustitución o revocación del documento y la firma del autor. Salvo que se establezca que una parte del documento anterior sigue teniendo validez, el otorgado con posterioridad revoca totalmente el anterior.

El documento de instrucciones previas deberá ser respetado por los servicios sanitarios, equipo médico responsable y por cuantas personas estén relacionadas con el declarante. En caso de dudas sobre su aplicación, podrán ser consultadas al Comité de Ética Asistencial del centro o, en su defecto, a la Comisión Específica constituida a tal efecto, salvo que en casos de urgencia no sea posible, quedando al criterio del 
facultativo responsable. Si el profesional sanitario alegase objeción de conciencia para su aplicación, la autoridad sanitaria dispondrá de los recursos necesarios para atender las instrucciones previas del paciente, según se recoge en el art. 5.

Determina el art. 6 que los posibles conflictos que pudieran surgir en la aplicación de estos documentos, serán solventados por la dirección del centro sanitario o, en su caso, por el Comité de Ética Asistencial, pudiendo solicitarse a estos efectos informe al Consejo Asesor Regional de Ética Asistencial.

En relación al lugar de presentación, estipula el art. 7 que se podrá entregar en el Registro de Instrucciones Previas de la Región de Murcia o en el centro sanitario donde sea atendido, pudiendo realizar este acto el otorgante, las personas vinculadas a él por relaciones de parentesco o de hecho o por su representante legal.

Como se dijo, en los arts. 8-13 del Decreto se procede a la regulación del Registro de Instrucciones Previas de la Región de Murcia.

Las funciones del Registro se recogen en el art. 9: inscripción, custodia, expedir certificaciones, garantizar el acceso, proporcionar información a los ciudadanos, coordinación con el Registro Nacional de Instrucciones Previas.

Se presentará por el otorgante, art. 11, pudiendo acceder a su contenido, el autor y su representante legal, el médico responsable de la asistencia sanitaria del otorgante, realizándose el acceso mediante un sistema que garantice la identidad de la solicitante, la información comunicada quedando constancia de la transmisión y fecha como se recoge en el art. 13.

\subsection{Comunidad Autónoma de Navarra}

\subsubsection{Ley Foral $17 / 2010,8$ de noviembre, Derechos y deberes de las personas en materia de salud en la Comunidad Foral de Navarra ${ }^{63}$}

El documento de voluntades anticipadas se regula en el Capítulo II del Título V, concretamente en los arts. $54^{64}$ y 55 , de la citada Ley Foral.

\footnotetext{
${ }^{63}$ B.O. Navarra n. 139, 15 de noviembre de 2010, p. 15023; B.O.E. n. 315, 28 de diciembre de 2010, p. 107659 .

64 "El documento de voluntades anticipadas es el dirigido al médico responsable en el cual una persona mayor de edad, o un menor al que se le reconoce capacidad conforme a la presente Ley Foral, deja constancia de los deseos previamente expresados sobre las actuaciones médicas para cuando se encuentre en una situación en que las circunstancias que concurran no le permitan expresar personalmente su voluntad, por medio del consentimiento informado, y que deben ser tenidos en cuenta por el médico responsable y por el equipo médico que le asista en tal situación. En las voluntades anticipadas se podrán incorporar manifestaciones para que, en el supuesto de situaciones críticas, vitales e irreversibles respecto a la vida, se evite el sufrimiento con medidas paliativas aunque se acorte el proceso vital, no se prolongue la vida artificialmente por medio de tecnologías y tratamientos desproporcionados o extraordinarios, ni se atrase abusiva e irracionalmente el proceso de la muerte. La persona en las manifestaciones de las voluntades anticipadas y a tal efecto, puede designar a un representante para cuando no pueda expresar su voluntad por sí misma. Esta persona será la única interlocutora válida y necesaria con el médico o el equipo sanitario. En la declaración de voluntad anticipada, la persona interesada podrá hacer constar la decisión respecto de la donación total o parcial
} 
Este documento deberá ser respetado por los servicios sanitarios y por las personas que tengan cualquier tipo de relación con el declarante. Se tendrán por no puestas las instrucciones contrarias al ordenamiento jurídico, a la buena práctica clínica, a la evidencia científica y las que no se correspondan con el supuesto de hecho que el sujeto haya previsto en el momento de emitirlas, debiendo en estos casos, hacer anotación razonada en la historia clínica.

El citado documento deberá ser entregado por el otorgante, familiares o representante al centro médico donde el sujeto sea atendido, incorporándose desde ese momento a la historia clínica del paciente.

En el art. 55 se estipulan los procedimientos de formalización y el Registro de voluntades anticipadas. Podrá realizarse: a- ante notario, no siendo precisa la presencia de testigos, $b$ - ante tres testigos mayores de edad, con plena capacidad de obrar, de los que al menos dos, no tendrán relación de parentesco hasta el segundo grado ni vinculados por relación de parentesco con el otorgante, c- ante funcionario o empleado público del Registro de Voluntades Anticipadas de Navarra, conforme a lo dispuesto reglamentariamente.

Los documentos de voluntades anticipadas podrán ser revocados, sustituidos o modificados libremente por el declarante, siempre que conserve su capacidad, siendo únicamente válido el otorgado en último lugar.

\subsubsection{Decreto Foral 140/2003, de 16 de junio, por el que se regula el Registro de Voluntades Anticipadas de la Comunidad Autónoma de Navarra ${ }^{65}$}

Los objetivos se establecen en el art. 2: recopilación y custodia de los documentos de voluntades anticipadas y acceso a los mismos de forma ágil por parte de los profesionales médicos. La solicitud para su inscripción se realizará por el otorgante, art. 3. Por último, en relación a las personas legitimadas para su acceso, se citan el autor, representante citado en el documento, representante legal en su caso y "el médico responsable o un miembro del equipo médico que se encuentre prestando asistencia sanitaria al otorgante del mismo", como se recoge en el art. 13.

\subsection{Comunidad Autónoma del País Vasco}

\subsubsection{Ley 7/2002, de 12 de diciembre, de las voluntades anticipadas en el ámbito de la sanidad de la Comunidad Autónoma del País Vasco ${ }^{66}$}

Consta de 7 artículos, 1 Disposición Derogatoria y 2 Disposiciones Finales.

\footnotetext{
de sus órganos para fines terapéuticos, docentes o de investigación. En este supuesto no se requerirá ninguna autorización para la extracción o utilización de los órganos donados”

${ }^{65}$ B.O. Navarra n. 81,30 de junio de 2003, p. 6663.

${ }^{66}$ B.O. País Vasco. n. 248, 30 de diciembre de 2002, p. 23318; B.O.E. n. 291, 3 de diciembre de 2011, p. 128916.
} 
Se determina en el $1^{\circ}$ artículo el objeto de la norma. En el art. 2 se detalla el contenido del documento, estipulando que cualquier persona mayor de edad que no se encuentre incapacitada judicialmente y actúe libremente "tiene derecho a manifestar sus objetivos vitales y valores personales, así como las instrucciones sobre su tratamiento, que el médico o el equipo sanitario que le atiendan respetarán cuando se encuentre en una situación en la que no le sea posible expresar su voluntad".

La finalidad de los objetivos vitales y valores personales es ayudar en la interpretación de las instrucciones y servir de orientación cuando el otorgante no pueda manifestar su opinión. Se pueden nombrar uno o varios representantes como interlocutores con el equipo médico y con facultades de interpretación del documento. Cualquier persona mayor de edad que no haya sido incapacitada judicialmente puede ser designada representante, a excepción de: "a-El notario, $b-E l$ funcionario o empleado público encargado del Registro Vasco de Voluntades Anticipadas, c-Los testigos ante los que se formalice el documento, $d-E l$ personal sanitario que debe aplicar las voluntades anticipadas, e-El personal de las instituciones que financien la atención sanitaria de la persona otorgante".

Si se ha designado como representante al cónyuge o pareja de hecho del declarante, la interposición de demanda de separación, divorcio o nulidad o finalización formalizada de la pareja o unión libre extinguirá la representación, salvo que en el primer caso conste expresamente en la resolución judicial al efecto el mantenimiento del mismo o en el segundo supuesto, se recoja en un nuevo documento.

El art. 3 determina que debe estipularse por escrito y puede realizarse mediante los siguientes procedimientos: a-ante notario, b-ante funcionario o empleado público encargado del Registro Vasco de Voluntades Anticipadas, c-ante tres testigos, mayores de edad, con plena capacidad de obrar y no vinculadas con el declarante por matrimonio, relación afectiva análoga a la conyugal, parentesco hasta el segundo grado de consanguinidad ni relación patrimonial.

El documento puede ser modificado o revocado en cualquier momento, siempre que el otorgante tenga capacidad y cumpla los requisitos exigidos en los artículos anteriores, siendo válido a todos los efectos el otorgado en último lugar, art. 4.

En tanto la persona conserve su capacidad y libertad de expresarse, su voluntad prevalecerá sobre lo dispuesto en el documento de voluntades anticipadas ante cualquier intervención clínica o tratamiento médico. Asimismo, serán ineficaces las estipulaciones contrarias al ordenamiento jurídico, o que no se correspondan con los tipos de supuestos previstos por el otorgante en el momento de formalizar el citado documento, así como aquellas relativas a las intervenciones médicas que el declarante desee recibir si son contrarias a su patología. Las contraindicaciones deberán ser anotadas y motivadas en la historia clínica del paciente, como dispone el art. 5.

En el art. 6 se determina la creación del Registro Vasco de Voluntades Anticipadas dónde se podrá inscribir voluntariamente los citados documentos que se han realizado. 


\subsubsection{Decreto 270/2003, de 4 de noviembre, del Gobierno Vasco, por el que se crea el Registro de Voluntades Anticipadas ${ }^{67}$}

Se creó en el plazo de 10 desde la promulgación de la norma como dispone la D.F. $1^{\text {a }}$. Se rige por los principios de confidencialidad e interconexión con otros Registros de la misma naturaleza, con el único objetivo de permitir el cumplimiento efectivo de las voluntades anticipadas de los otorgantes, no siendo preciso su consentimiento para tal comunicación.

El art. 7 dispone que si no se ha inscrito el documento de voluntades anticipadas en el Registro, debe ser entregado en el centro médico donde el otorgante sea atendido. En caso de estar registrado, también puede ser entregado voluntariamente. La entrega puede realizarla el propio declarante, sus familiares, el representante legal, el representante designado en el documento, o en caso de documentos inscritos, el Registro Vasco de Voluntades Anticipadas.

En el art. 2 del citado Decreto se establecen las funciones del Registro: inscripción, custodia, garantizar el acceso, proporcionar información a los ciudadanos, coordinación con el Registro Nacional de Instrucciones Previas.

En el art. 8 se dispone que solicitará la inscripción el otorgante y podrá acceder al mismo el médico que preste asistencia a dicha persona.

\subsection{Comunidad Autónoma de Valencia}

\subsubsection{Ley 10/2014, de 29 de diciembre, de Salud de Valencia ${ }^{68}$}

Dedica el art. 45 a la regulación de las voluntades anticipadas ${ }^{69}$. En el supuesto de objeción de conciencia por parte de algún facultativo para su aplicación, se dispondrán los medios necesarios para el cumplimiento de la voluntad del declarante.

$\mathrm{Su}$ formalización se realizará mediante los procedimientos establecidos reglamentariamente. Las voluntades pueden ser modificadas o dejarse sin efecto en cualquier momento por la sola voluntad del otorgante, dejando constancia por escrito de esta circunstancia.

\footnotetext{
${ }^{67}$ B.O. País Vasco n. 233, 28 de noviembre de 2003, p. 23021.

${ }^{68}$ D. O. de la Comunitat Valenciana n. 7434, 31 de diciembre de 2014, p. 32201; B.O.E. n. 35, 10 de febrero de 2015, p. 11133.

69 "A través del documento de voluntades o instrucciones previas, una persona mayor de edad o menor emancipada, con capacidad legal suficiente y libremente, manifiesta las instrucciones que sobre las actuaciones médicas se deben tener en cuenta cuando se encuentre en una situación en la que las circunstancias que concurran no le permitan expresar libremente su voluntad, pudiendo designar un representante. En la declaración de voluntades anticipadas, la persona interesada podrá hacer constar la decisión respecto a la donación de sus órganos con finalidad terapéutica, docente o de investigación. En este caso, no se requerirá autorización para la extracción o la utilización de los órganos donados.
} 
2.10.2. Decreto $168 / 2004$, de 10 de septiembre, de la Consellería de Sanidad, que regula el documento de voluntades anticipadas y crea el Registro centralizado de Voluntades Anticipadas de la Comunidad Valenciana ${ }^{70}$

Consta de dos Títulos. En el primero se regulan los distintos aspectos del documento de voluntades anticipadas y en el segundo, el Registro de los mismos.

Respecto a la definición del documento y su contenido, se mantiene lo estipulado en la Ley 10/2014. Se permite la designación de un representante como interlocutor válido ante el médico o equipo sanitario responsable, facultándole para interpretar sus declaraciones e instrucciones cuando no pueda expresar su voluntad. Puede ser representante cualquier persona mayor de edad no incapacitado, con las siguientes excepciones: " $a$ - El notario autorizante del documento, $b$ - -El funcionario o empleado público encargado del Registro Centralizado de Voluntades Anticipadas de la Comunidad Valenciana, $c$ - Los testigos ante los que se formalice el documento, $d$ - El personal sanitario que debe aplicar las voluntades anticipadas, e- En el ámbito de la sanidad privada, el personal con relación contractual, de servicio o análoga, con la entidad privada de seguro médico", art. 2.

Su formalización deberá realizarse en escritura pública ante notario o por escrito ante tres testigos. Se exigen que éstos sean mayores de edad, con plena capacidad de obrar; "dos, como mínimo, no tendrán con el otorgante relación por razón de matrimonio, pareja de hecho, parentesco hasta el segundo grado de consanguinidad o afinidad o relación patrimonial alguna”, conforme a lo dispuesto en el art. 3.

Es posible la modificación, sustitución y revocación del citado documento en cualquier momento por el declarante, cuando tenga la capacidad requerida y exprese libremente su voluntad. Debe realizarse por escrito o de forma indubitadamente, art. 4.

No obstante la eficacia del antedicho documento, en tanto el otorgante conserve su capacidad, su voluntad ante cualquier actuación clínica prevalecerá sobre lo establecido en el mismo. Si el cumplimiento de lo dispuesto en el documento produjera la objeción de algún facultativo, la entidad sanitaria deberá prestar los recursos suficientes para permitir el cumplimiento de la voluntad del declarante. Por último, se dispone que no podrán aplicarse las voluntades que sean contrarias al ordenamiento jurídico o a la buena práctica clínica o aquellas que no correspondan exactamente al supuesto de hecho que el sujeto ha previsto cuando las emitió.

En el Título II se regula el Registro Centralizado de Voluntades Anticipadas, en el que los otorgantes podrán inscribir el otorgamiento, modificación, sustitución o revocación de dichos documentos. Asimismo, se disponen las funciones del mismo, así como los principios rectores por los que debe regirse, art. 6 .

En referencia a la inscripción, distingue el art. 7 cuando haya sido formalizado mediante escritura pública -se realizará mediante presentación de copia auténtica o comunicación del notario autorizante- o cuando se haya otorgado ante tres testigos mediante presentación del otorgante, de cualquiera de los testigos o por el representante designado-.

\footnotetext{
${ }^{70}$ B.O. Generalitat Valenciana n. 4846, 21 de septiembre de 2004, p. 23375.
} 
El acceso al Registro se limita a la persona otorgante y al médico responsable de la asistencia del sujeto, tras su identificación como usuario del sistema y mediante firma electrónica avanzada, como reza el art. 9.

\section{CONSIDERACIONES FINALES}

A nuestro entender y en virtud de lo expuesto, se puede afirmar que actualmente en España existe una heterogénea y sobredimensionada regulación de las instrucciones previas que, sin embargo, no aseguran una correcta implementación de este documento ni su efectividad práctica.

Como hemos señalado con anterioridad, pese a la existencia de un sustrato común en su regulación, las diferentes normas autonómicas presentan diferencias en la reglamentación de los aspectos básicos de la figura, así como las relacionadas con el desarrollo legal de los Registros.

En relación a las primeras, se debe señalar que son diversas las denominaciones utilizadas para hacer referencia a la misma institución: instrucciones previas, voluntades anticipadas, declaración de voluntad vital anticipada...

Difieren, asimismo, los requisitos exigidos al otorgante; en la mayoría de las CCAA se exige capacidad plena pero algunas permiten su otorgamiento por menores emancipados o incluso, en determinadas circunstancias, por personas incapacitadas judicialmente.

Tampoco la regulación de la figura del representante presenta una homogeneización, siendo diferentes los requisitos exigidos y sus funciones. Algunas legislaciones regulan expresamente las personas, que por distintas razones, no pueden realizar tal función.

En relación a la forma de otorgamiento, es preciso indicar que la totalidad de las CCAA exigen la forma escrita impuesta por la norma estatal. Por otro lado, si bien es cierto que la mayoría regulan tres procedimientos legales para su formalización: ante notario, ante testigos, ante personal habilitado administrativamente, se observan diferencias en relación a los requisitos y número de testigos exigidos para la validez del proceso.

Respecto al contenido, la práctica totalidad de las legislaciones autonómicas determinan que podrán incluirse en el documento las indicaciones sobre el cuidado de la salud del otorgante, evitar el alargamiento de la vida artificialmente mediante tratamientos desproporcionados y la decisión sobre la donación de órganos y del cuerpo. Quizás sea este aspecto el de más difícil concreción, dado que es complicado para una persona prever todas las situaciones en los que se pudiera y encontrar y su decisión respecto de las mismas. Asimismo, la limitación establecida por la lex artis hace que en cierto sentido pudieran carecer de valor. Además, algunas normativas recogen la posibilidad de que se estipulen los objetivos vitales y valores personales o historia de valores, con el objetivo de orientar al personal facultativo en la toma de decisiones clínicas. 
De forma unánime, las legislaciones territoriales establecen como límites de las instrucciones, aquellas contrarias al ordenamiento jurídico o a la buena práctica clínica, así como las que no se correspondan con el supuesto de hecho previsto por la persona en el momento de emitirlas, lo que implica la imposibilidad, por ejemplo, de incluir en el documento previsiones sobre la eutanasia o el suicidio asistido, prohibidos en nuestro sistema legal.

En relación a los Registros, son múltiples las cuestiones que difieren: personal encargado, forma de inscripción...siendo, a nuestro entender, la más significativa la relativa a las diferencias existentes entre las personas que pueden inscribir el documento como aquellas legitimadas para su acceso. Además, respecto a su aplicación práctica, es notorio el desconocimiento de esta institución y no tan claro la consulta al Registro por parte de los profesionales de la sanidad.

Por todo ello, consideramos que la existencia en nuestro ordenamiento jurídico de una extensa y heterogénea normativa sobre las instrucciones previas o últimas voluntades, generan una cierta descoordinación legislativa. Sería deseable una mayor armonización de los distintos aspectos formales y materiales, superando las actuales diferencias existentes en relación a los requisitos, procedimientos...

\section{BIBLIOGRAFÍA}

ABELLÁN-GARCÍA SÁNCHEZ, F., "Estudio jurídico sobre el marco regulatorio de las instrucciones previas en España: Estado y Comunidades Autónomas", en Instrucciones Previas en España, Fundación Salud 2000, Granada, 2008.

ALONSO OLEA, M., "El consentimiento informado en medicina y cirugía", R.A.P, n. $155,2001$.

ALONSO OLEA, M., FANEGO DEL CASTILLO, F., "Comentario a la Ley 41/2002, de 14 de noviembre, reguladora de la autonomía del paciente y de los derechos y obligaciones en materia de información y documentación clínica", ed. Cívitas, Madrid, 2003.

ARBE OCHANDIANO, M., Estudio de las Instrucciones Previas en el ámbito sanitario a través del ordenamiento jurídico español. Tesis doctoral, Univ. Salamanca.

BELLVER CAPELLA, V., "Pasos hacia una bioética universal: el Convenio Europeo sobre Derechos Humanos y Biomedicina", coord. ROMEO CASABONA, C.M., El Convenio de Derechos Humanos y Biomedicina. Su entrada en vigor en el ordenamiento jurídico español, Publicaciones de la Cátedra Interuniversitaria, Fundación BBVA, Diputación Foral de Vizcaya, de Derecho y Genoma HumanoEditorial Comares, Bilbao-Granada, 2002.

CANTERO MARTÍNEZ, J., La autonomía del paciente: del consentimiento informado al testamento vital, ed. Bomarzo, Albacete, 2005.

GARCÍA HERNÁNDEZ, T., "Manual del médico clínico para evitar demandas judiciales", La Ley actualidad, 1999.

GÓMEZ RUBÍ, J.A. "Directivas anticipadas: la última oportunidad para ejercer la autonomía". JANO 2000, n. LX (1337). 
HERNÁNDEZ N., De la responsabilidad jurídica del médico, ed. Ateproca, Caracas, 1999.

LAVADOS M., SERANI, A. Ética clínica. Fundamentos y aplicaciones, ed., Universidad Católica de Chile, Santiago de Chile, 1993.

LÓPEZ SANCHEZ, C., Testamento vital y voluntad del paciente, ed. Dykinson, Madrid, 2003.

MARCO MOLINA, J., "El régimen jurídico de la extracción y del trasplante de órganos", La Ley, n. 5343, 2001.

MONTALVO JAASKELAINEN, F., Muerte digna y Constitución. Los límites del testamento vital, ed. Universidad Pontificia de Comillas, Madrid, 2009.

NUNES, R., "Dimensãoetica da abordagem do doente terminal", Cuadernos de BioÉtica, n. 5, 1993.

PALOMARES BAYO, M. y LÓPEZ Y GARCÍA DE LA SERRANA, J., (Coord.). El consentimiento informado en la práctica médica y el testamento vital. Análisis de la legislación europea, nacional y autonómica. Estudio de su evolución jurisprudencial, ed. Comares, Granada, 2002.

PERICO, G., "Testamento biológico e malatiterminali”, Aggiornamentisociali, n.11, 1992.

QUINTANA, O., Por una muerte sin lágrimas. Problemas éticos al final de la vida, Flor del Viento, Barcelona, 1997.

REBOLlEDO DELGADO, L., "Derecho Constitución I”, ed. Dykinson, Madrid, 2011

RODRÍGUEZ-ARIAS VAIHE, D., Una muerte razonable, ed. Desclée De Brouwer, Bilbao, 2005.

SÁNCHEZ-GONZÁLEZ, M.A., "Informe sobre instrucciones previas", en Bioética, religión y salud, coord., MARTÍN SANCHEZ, I., Comunidad de Madrid, Madrid, 1995

SILVA-RUIZ, F., "El derecho a morir con dignidad y el testamento vital"; Boletín de Información. Ministerio de Justicia 46/1651, 1992.

SOLOMON D, The principle of double effect. In: The Encyclopedia of Ethis, ed. LC Becker.

SOLSONA DURÁN, J.F., "Voluntades anticipadas: una herramienta para anticipar acontecimientos y facilitar la asistencia urgente". Emergencias 2007; n. 19.

SIURANA, J.C., Voluntades anticipadas. Una alternativa a la muerte solitaria, ed. Trotta, Madrid, 2005.

TUR FERNÁNDEZ, N. "El documento de Instrucciones Previas o testamento Vital. Régimen jurídico", Aranzadi civil, n. 10, 2004.

VALENCIA PINZÓN, G., "Aspectos de responsabilidad", Revista Médico legal, v. 7

VVAA, "Sobre las acciones médicas proporcionadas y el uso de métodos extraordinarios de tratamiento", Grupo de Estudios de Ética clínica de la Sociedad Médica de Santiago, Rev. med. Chile, v. 131, n. 6, Santiago, jun. 2003. 